\title{
WestVirginiaUniversity
}

THE RESEARCH REPOSITORY @ WVU

Graduate Theses, Dissertations, and Problem Reports

2016

\section{Spontaneous Combustion of South American Coal}

Brunno C. C. Vieira

Follow this and additional works at: https://researchrepository.wvu.edu/etd

\section{Recommended Citation}

Vieira, Brunno C. C., "Spontaneous Combustion of South American Coal" (2016). Graduate Theses, Dissertations, and Problem Reports. 6875.

https://researchrepository.wvu.edu/etd/6875

This Thesis is protected by copyright and/or related rights. It has been brought to you by the The Research Repository @ WVU with permission from the rights-holder(s). You are free to use this Thesis in any way that is permitted by the copyright and related rights legislation that applies to your use. For other uses you must obtain permission from the rights-holder(s) directly, unless additional rights are indicated by a Creative Commons license in the record and/ or on the work itself. This Thesis has been accepted for inclusion in WVU Graduate Theses, Dissertations, and Problem Reports collection by an authorized administrator of The Research Repository @ WVU. For more information, please contact researchrepository@mail.wvu.edu. 
Spontaneous Combustion of South American Coal

\title{
Brunno C. C. Vieira
}

Thesis submitted to the Statler College of Engineering and Mineral Resources

at West Virginia University

in partial fulfillment of the requirements for the degree

of

Master of Science in Mining Engineering

\author{
Yi Luo, Ph.D., Chair \\ Felicia Peng, Ph.D. \\ Brijes Mishra, Ph.D. \\ Department of Mining Engineering \\ Morgantown, West Virginia
}

2016

Keywords: Spontaneous Combustion, Coal, South American, Safety, Mine fires, Self- heating temperature Copyright 2016 Brunno C. C. Vieira 


\section{Abstract}

Many causes can lead to mine fires and explosions in coal mines but one of the most relevant cause is the spontaneous combustion of coal. This event can cause serious environmental consequences such as release of huge quantities of greenhouse effect gases such as $\mathrm{CO}_{2}$ and $\mathrm{CO}$, presents safety risks to the miners by igniting mine explosions, and also causes significant economic loss. Many countries in the world have faced these problems. In order to prevent and mitigate them, scientists develop methods to determine whether a coal deposit has propensity to spontaneous combustion or not.

Many methods have been developed around the world for the determination of the propensity of spontaneous combustion of coals such as the adiabatic method, the USBM empirical methods based on coal quality analysis. The methods, having their own advantages and limitations, are applicable to analyze every coal or just some specific ones. These methods were developed mainly in Australia, USA and China since these countries are the major victims of mine fires.

Despite the fact that mine fires have caused many problems around the world, South American coals and deposits have never been studied for their propensity to spontaneous combustion. So what are the chances that coal producers in Latin America like Colombia and Brazil can face this problem in a near future? What preventive measures the mine operators should take to ensure safe and smooth mining operation? What kinds of environmental issues the coal spontaneous combustion could bring the population living nearby the mines? To answer these questions, the author performed the following 
experimental analyses to determine the propensity of the South America's coals. The results are presented in this thesis.

- The adiabatic analysis will be used to determine the intrinsic reactivity of coal samples obtained from Colombia at low temperatures. The reactivity will be calculated exposing the coal to dry and moist environment.

- The thermogravimetry (TGA) will be used to determine the activation energy of the coal samples obtained and also to do the proximate analysis, which is important to the next step.

- Use the proximate analysis to find parameters like self-heating temperature, quantified coal rank using US coal band which can be used to serve as a quick estimate of self-heating potential of South American coals. 


\section{Acknowledgement}

I would like to use this opportunity to thank the Brazilian people and institutions for providing the opportunity for me to further my education for a Master degree in Mining Engineering and, mainly, for believing that its students are able to live abroad and then return more experienced and capable to help to develop the country.

My family and friends were also very important during this time. Thanks, Wagner Vieira, Maria Vieira, Michelle Souza, Amanda Mora, Aanand Nandula, Neel Gupta, Hua Jiang, all my new friends from India, China, EUA and old friends from Brazil.

I wish to thank the companies Cerrejon in Colombia and CRM (Compania Riograndense de Mineração), especially to Nestor Monroy and Rodrigo Duarte for providing samples, information and support.

Last but not the least, I would like to thank the Mining Engineering Department of West Virginia University, especially to Dr. Yi Luo for his valuable guidance, Dr. Felicia Peng for the support and Dr. Brijes Mishra for being in the committee. 


\section{Table of Contents}

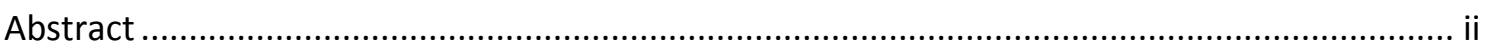

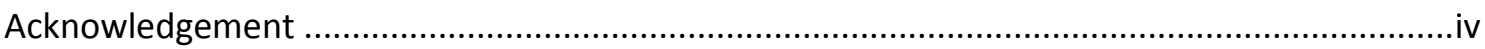

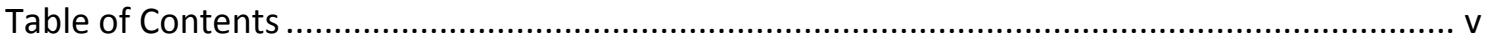

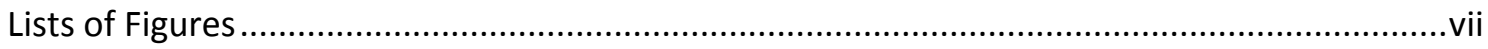

List of Tables.....................................................................................................................

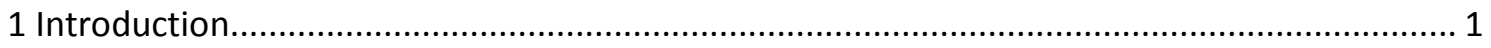

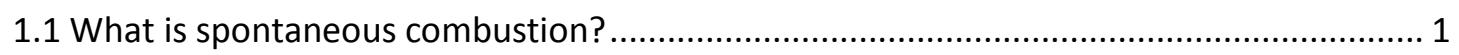

1.2 The hazards and economic lost caused by spontaneous combustion of coal .................... 2

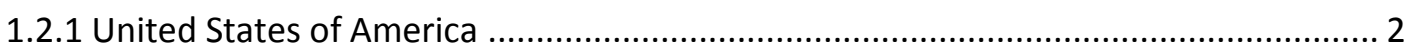

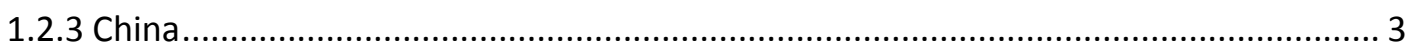

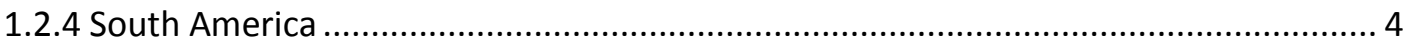

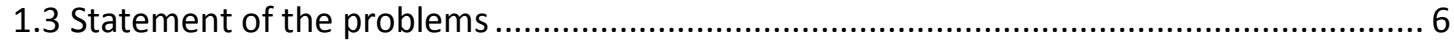

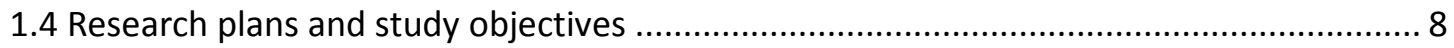

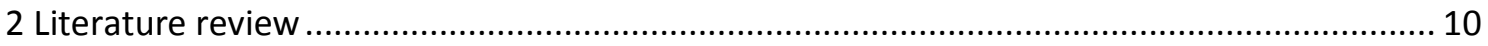

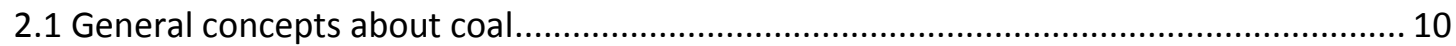

2.2 General Factors Influencing Spontaneous Combustion of Coal......................................... 11

2.2.1 Chemical Properties of Coal Influencing SCC ......................................................... 12

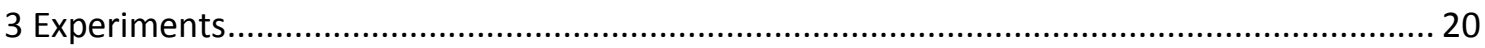

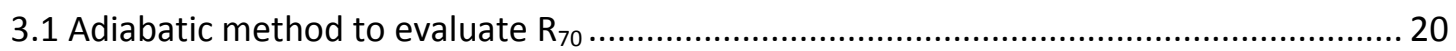

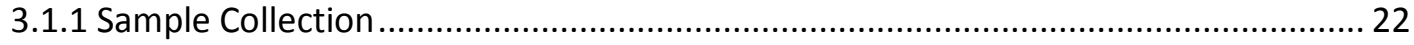

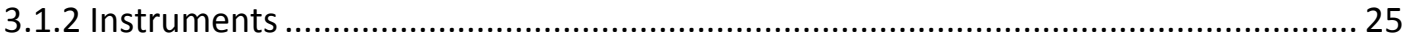

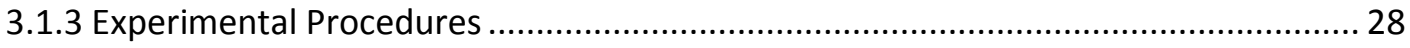

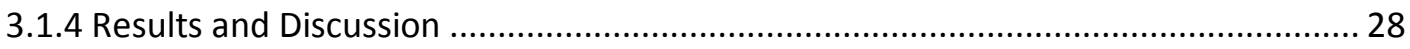

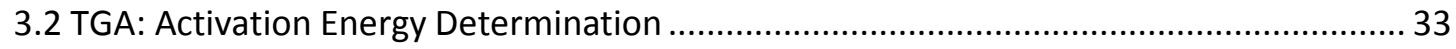

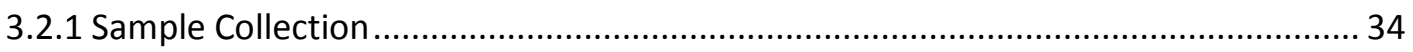

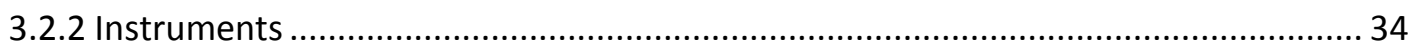

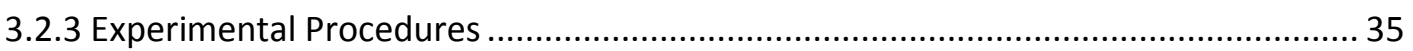

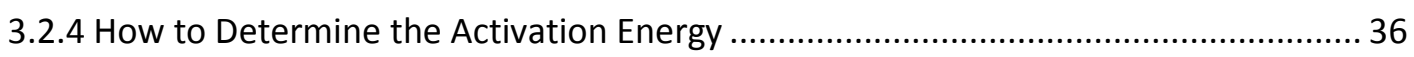

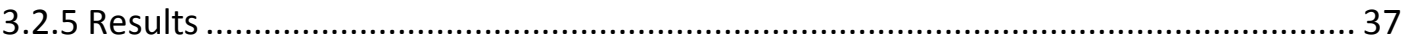

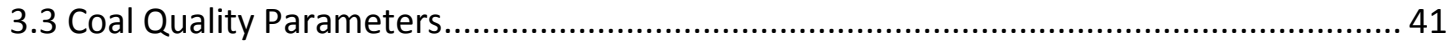

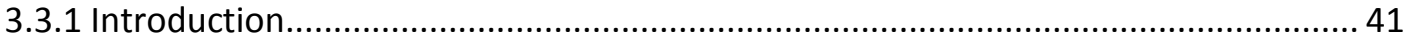




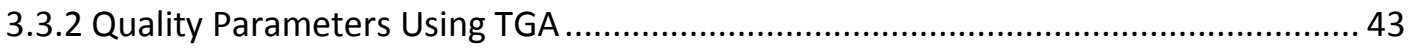

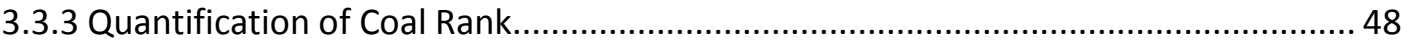

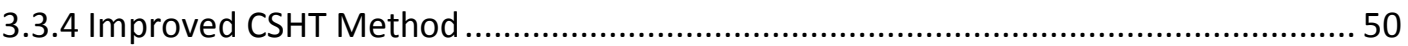

3.3.5 Correlation between Quantified Coal Rank (QCR) and SHT ................................... 51

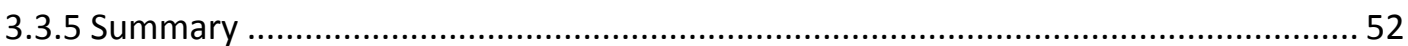

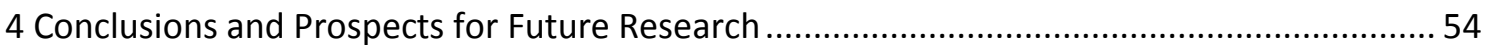

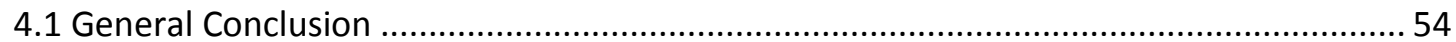

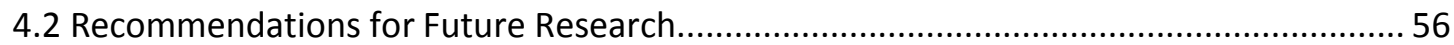

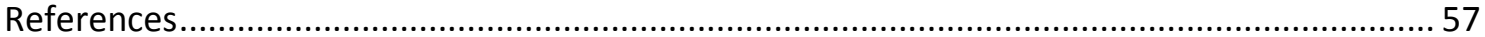




\section{Lists of Figures}

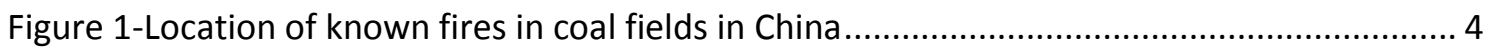

Figure 2- Reserves to Production Rates in South America (bpstats)......................................... 5

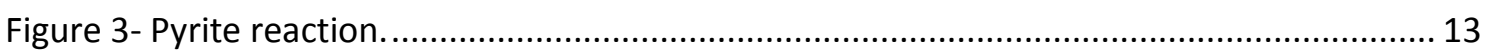

Figure 4-Variatin in Coal Composition with Rank (Baughman, 1978) ....................................... 16

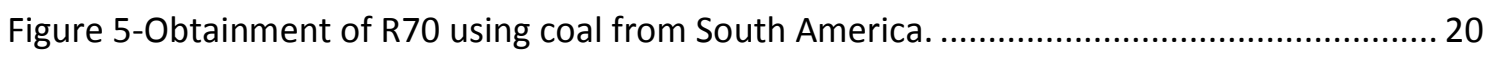

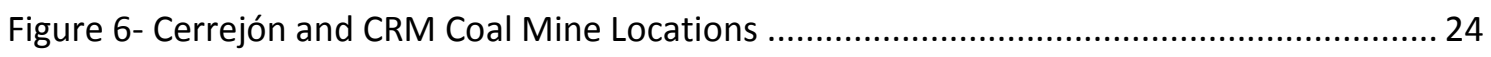

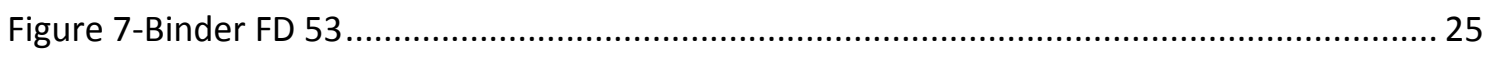

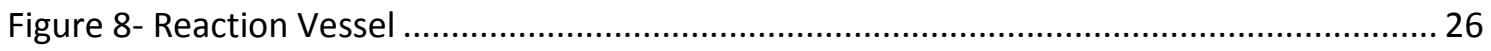

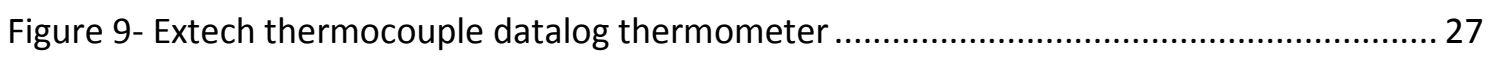

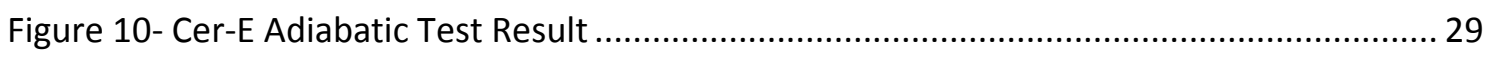

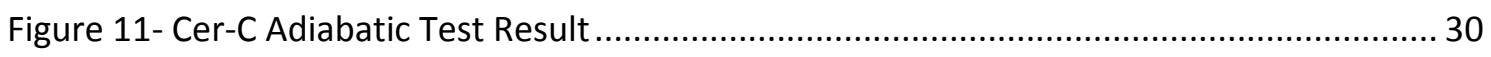

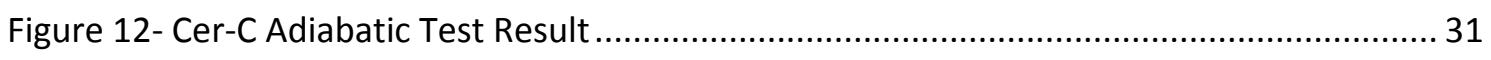

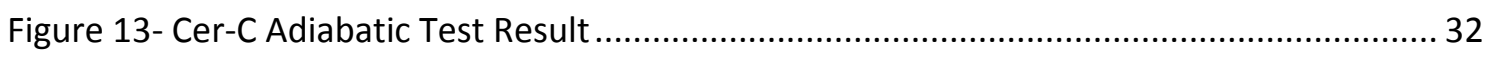

Figure 14- $\mathrm{R}_{70}$ curves of Colombian coal samples in moist environment .................................. 32

Figure 15- Weight as a function of temperature used to determine activation energy of coal. 33

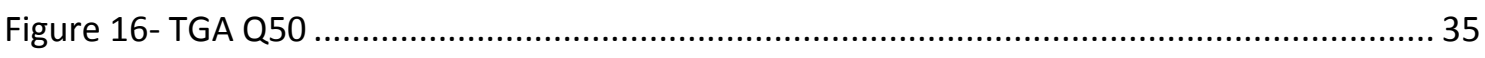

Figure 17- Regression used to determine the activation energy of coal .................................. 37

Figure 18- Weight as a function of time of coal Cer-E used to determine activation energy..... 38

Figure 19- Weight as a function of time of coal Cer-D used to determine activation energy .... 38

Figure 20-Weight as a function of time of coal Cer-Dm used to determine activation energy. 39

Figure 21- Weight as a function of time of coal Cer-C used to determine activation energy .... 39

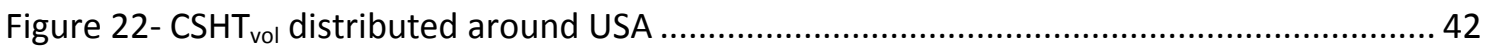

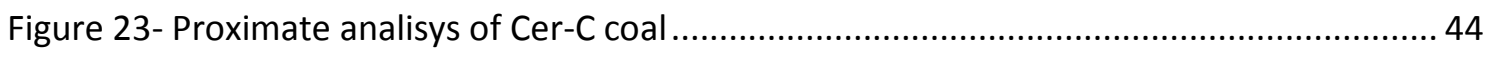

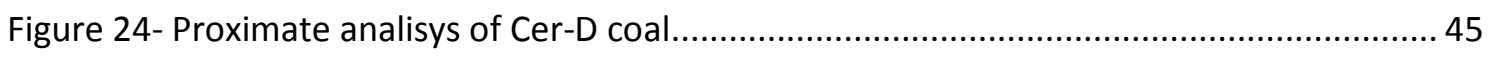

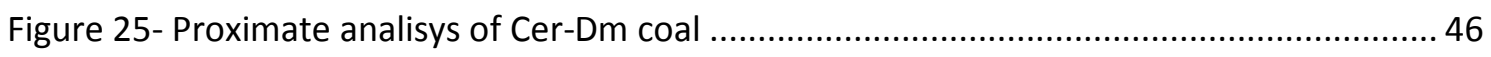

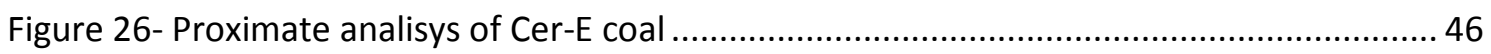

Figure 27 Quantified coal rank where green dot represents CRM coal and purple dots

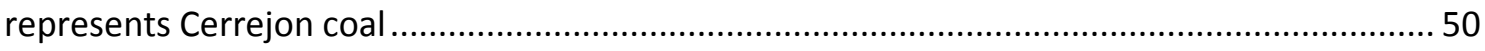

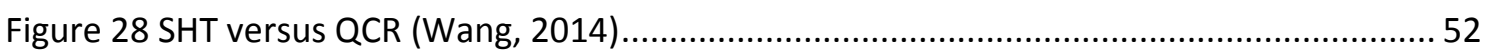




\section{List of Tables}

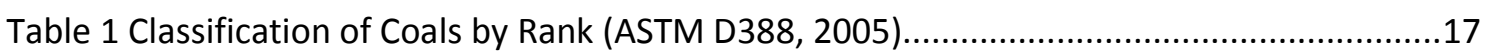

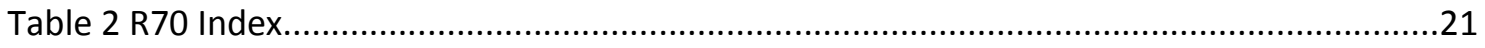

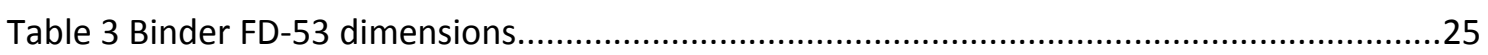

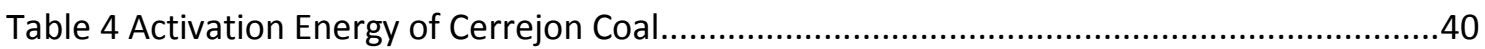

Table 5 Activation energy of coals from US and China (Wang, 2014).......................................41

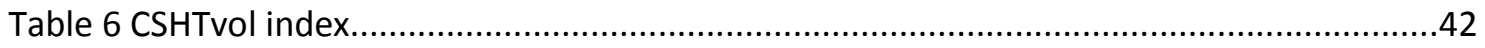

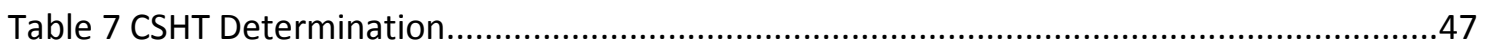

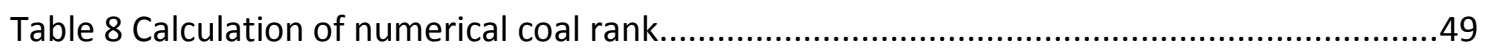

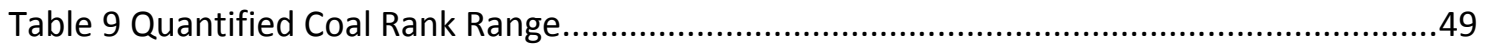

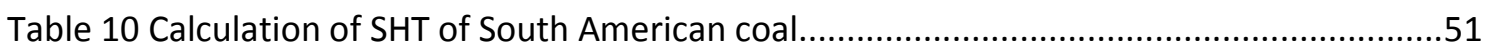

Table 11 Summary of the parameters calculated to charachterize propensity to spontaneous

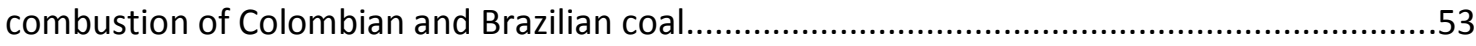




\section{Introduction}

\subsection{What is spontaneous combustion?}

The definition given by ITC (International Institute for Geo-Information Science and Earth Observation) to spontaneous combustion of coal is "The term 'spontaneous combustion' means that coal can start to burn without any recognizable outer influence. It is caused by coal's ability to react with oxygen in the air. As a result of the oxidation process the temperature of the coal starts to rise. If the temperature reaches a certain temperature, noxious gases such as carbon dioxide are produced. Finally, if the temperature still continues to rise the coal reaches the flash point and starts to burn. Spontaneous combustion depends, amongst others, on coal type, environment temperature, availability of oxygen, exposure surface, thickness of coal seam, as well as methods of mining."

Hartman, in his book Mine Ventilation and Air Conditioning states "Spontaneous combustion fires in coal mines are the result of oxidation of coal under conditions that allow the heat of oxidation to be partially retained in the coal until the self-ignition temperature is achieved" (Hartman, 1998).

So, when the coal reacts with oxygen exothermically, with no outer heat source to initiate this reaction, the environment is such that part of the heat generated will be stored, the stored heat will raise the coal temperature until the self-ignition temperature is reached. At this point, the process is called spontaneous combustion of coal. 


\subsection{The hazards and economic lost caused by spontaneous combustion}

of coal

\subsubsection{United States of America}

Spontaneous combustion continues to pose a hazard for U.S. underground coal mines, particularly in western mines where the coal is generally of lower rank. The risk of an explosion ignited by a spontaneous combustion fire is also present in those mines with appreciable levels of accumulated methane. Many coalfields in the USA are subject to spontaneous ignition. The federal Office of Surface Mining (OSM) maintains a database (AMLIS) showing 150 fire zones in US coal fields in 1999. In mid-2010, according to OSM, more than 100 fires were burning beneath nine states, most of them in Colorado, Kentucky, Pennsylvania, Utah and West Virginia. But geologists say many fires go unreported, so that the actual number of them is about 200 in 21 states (Cray, 2010).

Approximately $15 \%$ of the 164 total reported fires for underground coal mines in the period 1978-1990 were caused by spontaneous combustion. For the period 1990-2006, more than 20 U.S. coal mines suffered underground spontaneous combustion events, and 25 total reported fires for underground coal mines were caused by spontaneous combustion. The incidence of spontaneous combustion fires and the resulting explosion hazard in underground coal mines are expected to increase with the projected increasing mining operations in lower rank coals, deeper mines with more methane, and the growth in the dimensions of longwall panels. 
The Office of Mine Safety and Health Research (OMSHR) is working to reduce the spontaneous combustion risk in underground coal mines through the development of control methods and nitrogen injection strategies to prevent spontaneous heating. The control methods include: (1) optimizing the ventilation system to eliminate the possible critical velocity zones where the spontaneous heating will likely occur, (2) selecting an appropriate face advance rate to prevent the coal oxidation behind the shields not to reach a thermal runaway, and (3) early detecting of spontaneous heating to allow for enough time to suppress the heating (OSMR).

\subsubsection{China}

China is currently the world's largest coal producer and consumer. It depends on coal for about 75 percent of its annual energy production and consumes about half the world coal production (Rennie, 2002). It is estimated that of $1.3 \mathrm{Gt}$ produced every year (World Coal Institute, 1998) between 100 and 200 Mt of high quality coal is consumed by spontaneous combustion of coal.

The consumption of coal by spontaneous combustion carries with it many worrying problems. As mentioned before, the amount between 100 and $200 \mathrm{Mt}$ of coal consumed by SCC represents five to ten time the Chinese annual coal export. It means a waste of a valuable mineral resource and money. We also can quote some environmental problems, such as this amount represents $2 \%$ $3 \%$ of world's carbon dioxide production due to fossil fuels (ITC).

Depending on the situations, locations, depths, sizes or ages of the coal fires, there are different existing techniques that can be operated alone or used 
in combination, to extinguish coal fires. The common methods are water cooling or liquid nitrogen injection, burning coal removal by bulldozing or blasting, cutting off air supply by covering and/or filling cracks with soil or slurry. However, it is very hard to entirely eliminate the spontaneous combustion problem in China. China is huge in area and its coal reservoirs are widely spread as well as the mine fires as shown in Fig. 1. The detection of underground mine fires caused by spontaneous combustions often is very difficult.

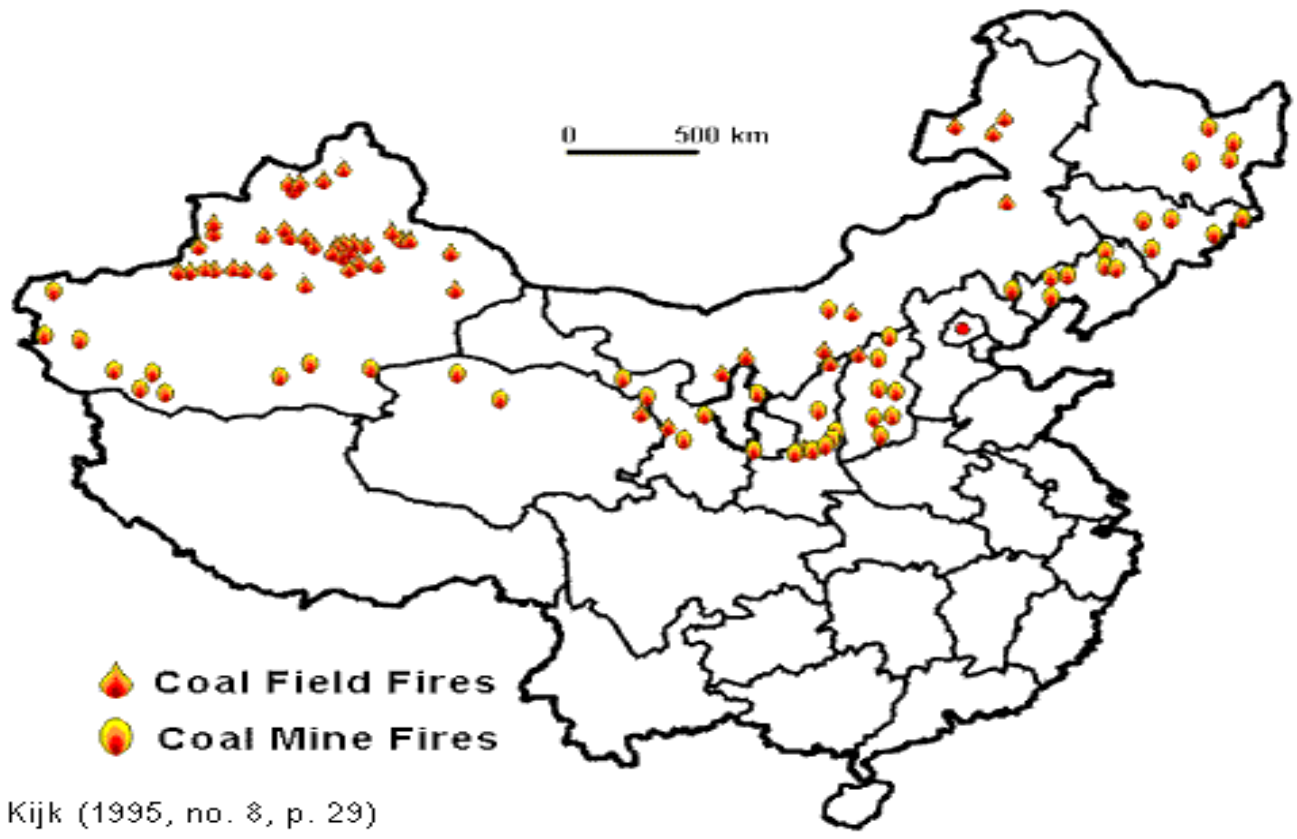

Figure 1-Location of known fires in coal fields in China

\subsubsection{South America}

The main coal reserves in South and Central America are located in Colombia (6746 Mt), Brazil (6630 Mt), Venezuela (479 Mt) and others (786 Mt) which represents $0.8 \%, 0.7 \%, 0.1 \%$ and $0.1 \%$ of the total proved reserves of coal in the world at end 2014, respectively. 
Colombia is by far the main producer of coal in Central and South America producing 55.6 Mt, followed by Brazil (3.2 Mt), Venezuela (1.9 Mt) and others $(1.7 \mathrm{Mt})$, representing $1.5 \%, 0.1 \%, 0.1 \%$ and less than $0.05 \%$ of world coal production, respectively.

About the coal consumption, Brazil consumes $15.3 \mathrm{Mt}$ (about $0.4 \%$ world consumption), Chile consumes 6.8 Mt (0.2\%) and Colombia consumes $4.2 \mathrm{Mt}$ $(0.1 \%)$.

The overall reserve, production and consumption in South and Central America are $14,641 \mathrm{Mt}$ (1.6\% share of total), $65 \mathrm{Mt}(1.7 \%)$ and $31.6 \mathrm{Mt}(0.8 \%)$. The ratio of coal reserve to production in South America is the third in the world as shown in Fig. 2. It indicates that the potential for coal mining in South and Central America to grow in future is high.

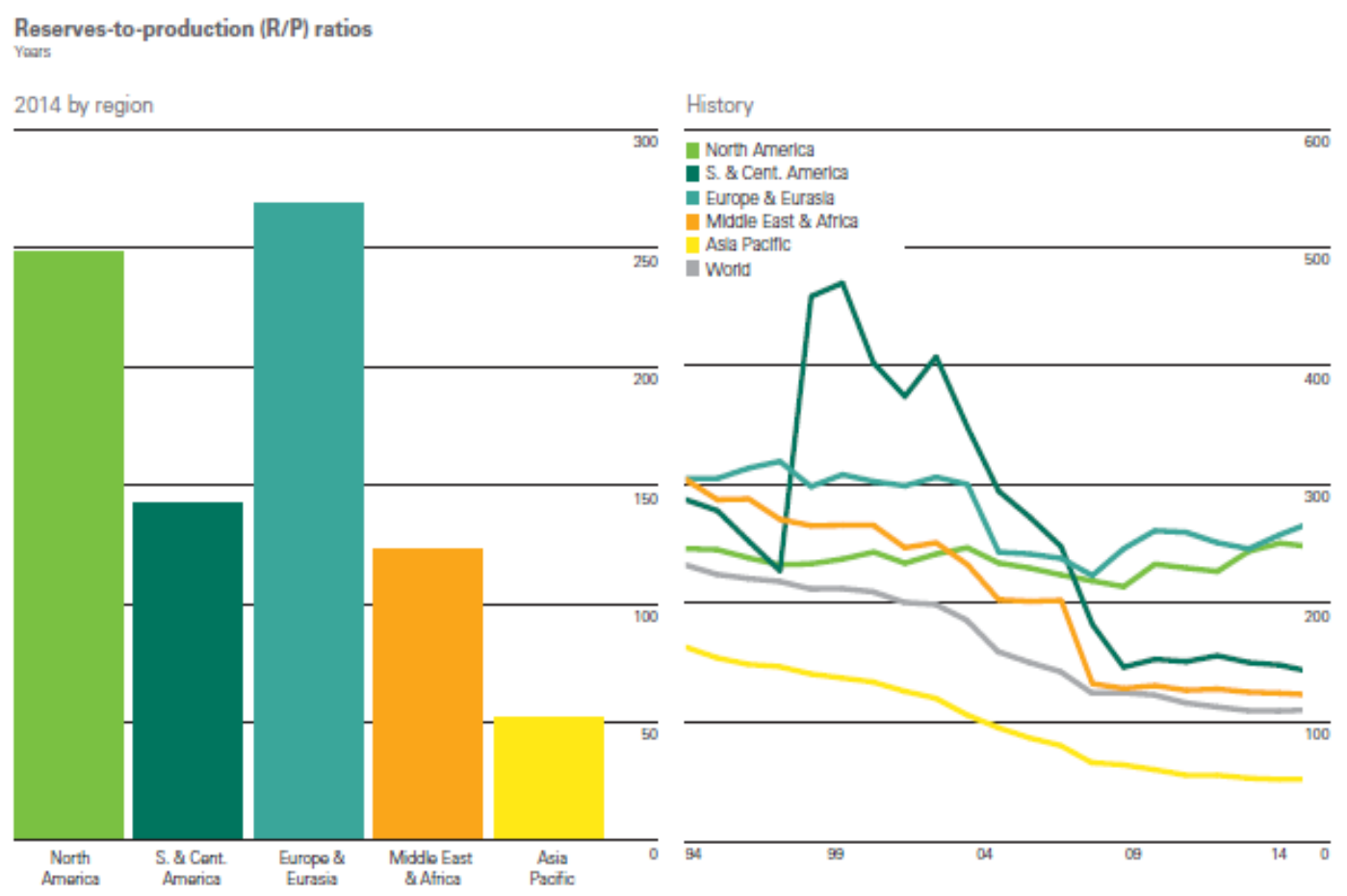

Figure 2-Reserves to Production Rates in South America (bpstats) 
The previous information about the South American coals shows that its coal production, consumption and reserves are relevant to the world's economy and also its production represents an important source of energy.

Since the propensity of coals' spontaneous combustion in South America has never been studied before, the risk for such phenomenon to cause hazards, economy loss and environmental damage is hard to be assessed. It is important to point out that the problems generated by coal fires do not happen only in U.S and China. Australia, South Africa, Germany, Indonesia, India also face this problem. Therefore, it is possible to conclude that coal fires generated by spontaneous combustion of coal or other sources of heat is a worldwide environmental, economic and safety problem that deserve adequate attention and science applied to understand and solve or mitigate this issue.

\subsection{Statement of the problems}

The chemical composition shows that coals consist of a wide range of organic structures as macromolecular building blocks and have extremely complex molecular structures. A number of network models for coal structure have been proposed. But these are established mainly based on general structural properties and cannot represent the real coal structures - even coals with the same rank can have very different chemical structures. Although the molecular structure of coal has been controversial, it is generally agreed that both low-molecular weight compounds (molecular weight less than 500) and macromolecules (molecular weight larger than 500) coexist in coal (Yu, 2013). This uncertainty about the coal structure also generates an uncertainty about an 
important process of spontaneous combustion - the coal oxidation mechanism. Despite of it, most of the researchers agree that the reaction of oxygen with coal is a surface phenomenon and proceeds through a loosely bound coal-oxygenwater complex with subsequent steps being breakdown of the complex to simpler molecules such as $\mathrm{CO}, \mathrm{CO}_{2}$ and $\mathrm{H}_{2} \mathrm{O}$ etc. (Singh, 2013).

Spontaneous heating appears only in certain seams and these capable/susceptible seams are frequently adjacent to seams acted by the same method and submitted to the same tectonics, but which have never been the site of combustion. Some seams have only been susceptible in one area and, again, some seams are more susceptible than others. Most of the major fires were in shallow workings originating from workings along the outcrops and abandoned opencast mines. In case of thick seams invariably, coal is left in the gob after the extraction of pillars. The gob is generally connected through cracks to surface following subsidence. These cracks feed fresh air to the gob where coal oxidizes. Coal catches fire due to spontaneous heating and the fire spreads out over bigger areas.

Many underground mines have been converted into opencast to augment the production. In such cases heated up areas catch fire after exposure to the atmosphere. Besides these, there are fires in coal stack, in developed galleries worked by opencast method, washery rejects and overburden dumps etc (Singh, 2013).

From what was said previously, we can see that it is hard to determine the potential of spontaneous combustion of coal because it depends on plenty of factors like seam factors such as rank, petrographic composition, temperature, available air, particle size, moisture, sulfur, effect of previous 
oxidation, other minerals, etc; geological factors: seam thickness, seam gradient, caving characteristics, coal outburst, friability and, finally, mining factors: mining methods, rate of advance, pillar conditions, crushing, humidity.

Despite the difficulties said before, self-heating incidents in underground coal mines often occur in gob or sealed areas and may not be easily detectable. In storage and shipment conditions, spontaneous combustion normally starts under the surface of the coal storage pile and may not be detected initially. Therefore, a better understanding about the propensity of spontaneous combustion of coal could greatly benefit the scheduling of these coal handling operations, design of the ventilation system as well as mining operations in coal mines.

The nescience about propensity of spontaneous combustion of coal in South America is the major problem and concern of this dissertation; moreover the influence of moisture in the air will also be also investigated here by analyzing empirical results.

\subsection{Research plans and study objectives}

The major objectives of this work are: (1) to improve the determination accuracy of the spontaneous combustion propensity by considering the air moisture influence, and (2) to classify the propensity of some samples of South American coals to ignite spontaneously. It is hoped that this study will be used for improving safety in existing and future coal mines in South America. 
Samples of coal from the main coal producing countries in South America have be requested and then analyzed using TGA and $R_{70}$ testing setups in the West Virginia University's ventilation laboratory.

The first experiments done using the coal samples obtained will be the adiabatic test. Here it is possible to determine the values of $R_{70}$, one of the most important parameters to determine spontaneous combustion propensity.

The TGA method will be used for determining the activation energy and proximate analysis of the coal samples. The results obtained will be used to determine parameter that classify the coal about its propensity to spontaneous combustion. 


\section{Literature review}

\subsection{General concepts about coal}

Coals are sediment, organoclastics in nature, composed of lithified plant remains. They have the important distinction of being combustible materials. The composition and character of each coal will be determined firstly by the original organic and inorganic matter accumulated, and then the diagenesis degree.

The type of coal is defined by the composition and ratio of the organic equivalent of minerals and mineral matter, the inorganic fraction made up of a variety of primary and secondary minerals

Coal rank is the degree of diagenesis or coalification that a coal has undergone by burial and tectonic effects. Coal rank is divided into lignite, sub bituminous, high volatile bituminous, medium volatile bituminous, low volatile bituminous, semi anthracite and anthracite. But sometimes the terms brown coal and black coal are used to refer to low rank and high rank respectively.

The noncombustible inorganic fraction of coal is known as its mineral content. They are separated into two different groups; detrital, mineral matter transported into a swamp by air or water. Examples are quartz, carbonate, iron and clay minerals. The other group is the authigenic composed by mineral introduced in the peat during or after deposition, or into a coal during the coalification for example calcite, ankerite, siderite and pyrite, which is very important to determine the potential of spontaneous combustion of coal, something that will be discoursed latter. 


\subsection{General Factors Influencing Spontaneous Combustion of Coal}

It was said previously that the composition of coal depends on the original organic and inorganic matter, as well as diagenesis degree. So it is obvious that it would be very hard to find identical coals from different places. The plant debris consisted of several thousand species. The relative amounts of similar types of plants vary considerably in different ranks of coals. On this basis, coal differs markedly in composition from one location to another. As a result, coal has many properties that affect its ability to combust and to spontaneously ignite (Wang, 2014).

To limit the focus of the studies, it is important to know what influences in the propensity of spontaneous combustion of coal. Formerly, researchers used to consider the pyrite the sole cause but now we understand that the propensity of spontaneous combustion depends on a number of factors. Davis and Reynolds state that factors known and thought to affect the self-heating of coal may be classified on a physical - particle size, oxygen supply, temperature and ventilation- and chemical basis - pyrite, rank of coal, weathering, moisture, organic sulfur- according to the character of the influence exerted while Later Guney (1968) classified the factors into intrinsic - pyrites, moisture, particle size and surface area, rank and mineral matter - and extrinsic categories temperature, pressure, oxygen concentration, ventilation system, bacteria. Moisture and pyrite may exert both chemical and physical influence. The chemical factors will be discussed below. 


\subsubsection{Chemical Properties of Coal Influencing SCC}

Coal can be considered as being made up of moisture, pure coal and mineral matter. The moisture consists of surface moisture and chemically bound moisture and the pure coal is the amount of organic matter present. The mineral matter is the amount of inorganic matter material present that produces ash when the coal burn.

Coal analysis is divided in two, proximate and ultimate analysis. The proximate analysis determines the amount of moisture, volatile matter, fixed carbon and ash. The ultimate analysis is the determination of the chemical elements of coal, carbon, oxygen, nitrogen and sulfur. The proximate analysis is the most fundamental of all coal analyses and is of great importance in the practical use of coal. When it comes about spontaneous combustion, the importance of the proximate analysis is evident since most of the properties determined influence on it (Thomas, 1992).

\subsubsection{Pyrite}

Some coals with very low sulfur content may ignite, yet it does not mean that the pyrites is not a factor in other cases. Previous investigations have shown that any form of pyrites, when finely ground, will adsorb oxygen and enter into heat producing reactions. Furthermore, due to its low specific heat, pyrite will heat up faster than coal and it may act as booster for further oxidation activities (Joseph and Reynolds, 1928).

The heat production of the oxidation of pyrites has been studied by Parr and Kressman. The reaction is generally represented by the following equations 
(The complete reaction can be seen in Parr and Kressmann, 1910, "The Spontaneous Combustion of Coal”):

$$
2 \mathrm{FeS}_{2}+7 \mathrm{O}_{2}+2 \mathrm{H}_{2} \mathrm{O}=2 \mathrm{FeSO}_{4}+2 \mathrm{H}_{2} \mathrm{SO}_{4} \quad \Delta \mathrm{H}=-62,4 \mathrm{Kcal}
$$

Recent and excellent studies done by Rimstidt and Vaughan tried to demonstrate how to dissect the process of aqueous oxidation to reveal each of the elementary reaction steps and hence determine the key controls of reaction mechanisms and rates. They consider that the pyrite oxidation is an electromechanical process that consists in three different steps as illustrated in the figure 3. The steps are (1) cathodic reaction, (2) electron transport, and (3) anodic reaction. Despite these process are discussed separately, they must occur almost simultaneously.

Conclusions from their studies are; the oxidation of pyrite is a complex electromechanical process requiring the transfer of seven electrons from each sulfur atom through the semiconducting crystal to an oxidant.

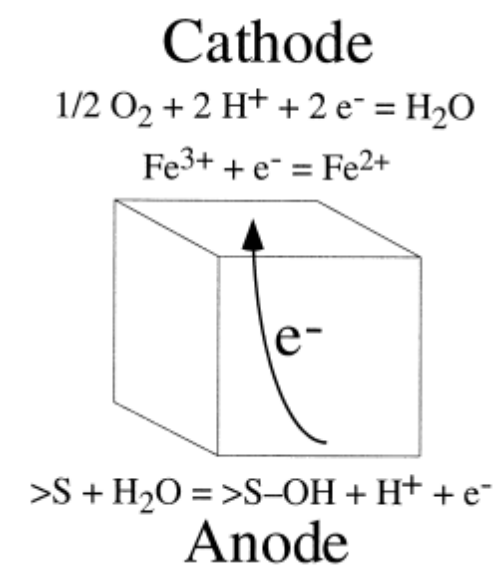

Figure 3- Pyrite reaction.

It is important to point out that the reaction 2.1 is the result of complex reactions. Wang observed that the stages of the reaction that have water 
involved liberate more heat, are more exothermic. From Le Chatelieur's principle we can say that increasing the concentration of any reagent, the system readjusts itself to counteract the effect of the applied change and a new equilibrium is established. It was said because future research can be focused in analyzing whether rain over stock piles or subsurface water will increase the water concentration of such reaction and, consequently, the equilibrium would shift to consume this extra water generating more heat.

Joseph and Reynolds came out with important conclusions about the influence of pyrite in spontaneous combustion of coal; under suitable conditions the pyrites in coal will oxidize rapidly and may be a dominant factor in certain cases for the self-heating of coal, marcasite and pyrite oxidize with about the same rate but marcasite breaks down more easily producing fine particles, thus facilitating the oxidation, the rate of oxidation of pyrite and marcasite is directly proportional to temperature and inversely proportional to the diameter of the particles, again dry air and oxygen does not promote the oxidation of the pyrite, high textural moisture seems to be accompanied by rapid oxidation of pyrites.

\subsubsection{Moisture}

Different types and ranks of coal can have different capacity to contain water in its structure as it is shown in the figure 4 . In that figure we can see that as lower the rank of the coal, higher is the capacity of this coal adsorb water.

It is know that the water condensation is an exothermic reaction, when vapor of water, high energetic state, becomes liquid water, lower energetic state, energy is liberated. See the physical transformation represented below:

$$
\mathrm{H}_{2} \mathrm{O}_{v} \rightarrow \mathrm{H}_{2} \mathrm{O}_{l} \quad \Delta \mathrm{H}_{\text {condensation }}=-2257 \mathrm{~kJ} / \mathrm{kg}
$$


These two last pieces of information, capacity of coal to absorb water and water condensation been an exothermic transformation, are important to reach the following conclusion: Coal not saturated with liquid water in contact with humid air will adsorb this environment vapor, transforming it into liquid water and also retaining part of the energy liberated. This energy will heat up the coal, contributing significantly to increase the risk of spontaneous ignition. As it was said, this process is more determinant on SCC propensity in low rank coal.

The moisture content in different ranks of coal with different total moisture contents during the oxidation can affect the propensity of SSC in different way, also for different ranks of coal there are different critical moisture content, moisture that make that coal have the highest propensity to SCC, it was shown that for lignite and anthracite, the critical moisture content is $25 \%$ and $20 \%$, respectively (Xu, et al, 2013).

\subsubsection{Rank of Coal}

The rank of coal is the metamorphic grade increase following the order: peat, lignite, sub-bituminous, bituminous, anthracite and graphite.

It is important to point out that only ideally coal rank parameter should exhibit a distinct change associated with only metamorphic temperature but in real world no single parameter is useful over the entire coal rank range. It is possible to base the differences of coal rank on vitrinite reflectance but it can generate problems in lower coal rank, chemical rank base the coal rank in maceral and chemical and non-mineral inorganic geochemistry, also coal rank classification based on vitrinite concentrates are suspect if comparison are made between samples in organic sulfur. 
We can say that the mechanism of coal rank is a function of the combination of heat, pressure and time. Hilt's law is used to show the implication of coal rank and burial depth considering that as greater is the depth higher is the temperature.

Some important physical changes in coal associated with the increasing rank are decrease of moisture, increase of heating value and increase of density (O'keefe, et al, 2013). See the figure below to see changes in proximate analysis associated with the coal rank.

PERCENT

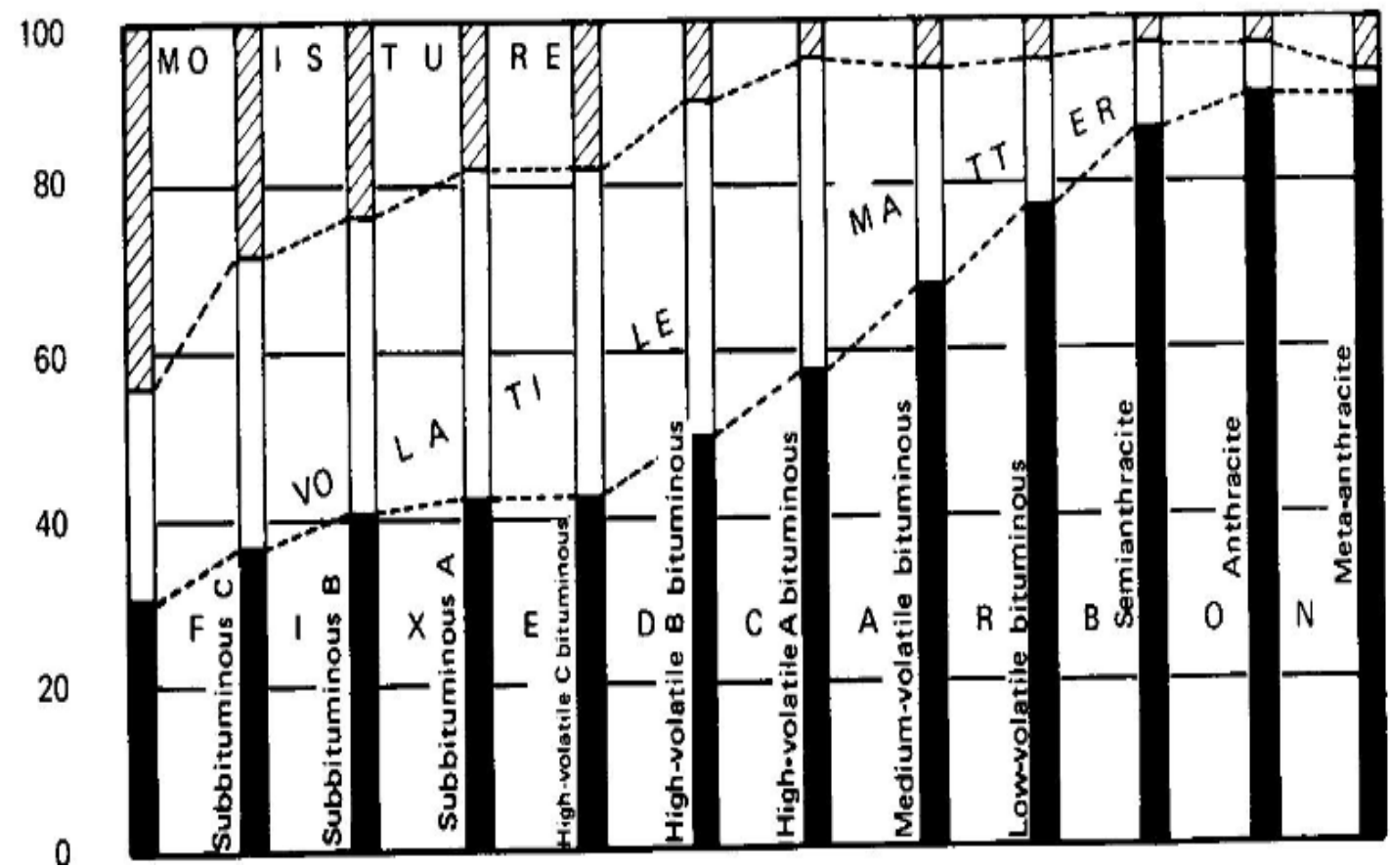

Figure 4-Variatin in Coal Composition with Rank (Baughman, 1978)

In this thesis the most important to be said about coal rank is how coal rank affects the susceptibility of coal to the spontaneous combustion. A study investigated the spontaneous combustion susceptibility of Chinese bituminous and Indonesian lignite coal by combining the CPT (critical point temperature) 
measurement and the gas analysis, the conclusion was that the lower the coal rank, the more the coal has a substance that can react with oxygen even at low temperature (Wantaek, et al, 2012). Another experiment using $\mathrm{R}_{70}$ self-heating experiment showed that sub-bituminous coal has 20 times the $R_{70}$ rate comparing to the high volatile bituminous (Beamish, 2005). This difference use to be attributed to the petrographic constituents of coal. In conclusion, the susceptibility to spontaneous combustion in low rank coals is higher than in high rank coals.

The coal rank will be determined using the method developed by the American Society for Testing and Materials (ASTM) and used in Canada and United States. The ASTM coal rank is shown in Table 1.

Table 1 Classification of Coals by Rank (ASTM D388, 2005)

\begin{tabular}{|c|c|c|c|c|c|c|}
\hline \multirow{2}{*}{ Class and group } & \multicolumn{2}{|c|}{$\begin{array}{l}\text { Fixed carbon } \\
(\mathrm{dmmf}, \%)\end{array}$} & \multicolumn{2}{|c|}{$\begin{array}{l}\text { Volatile matter } \\
\text { (dmmf, \%) }\end{array}$} & \multicolumn{2}{|c|}{$\begin{array}{c}\text { Calorific value } \\
\text { (moist dmmf, Btu per } \\
\text { lb) }\end{array}$} \\
\hline & $\begin{array}{l}\text { Equal or } \\
\text { greater } \\
\text { than }\end{array}$ & $\begin{array}{l}\text { less } \\
\text { than }\end{array}$ & $\begin{array}{l}\text { Greater } \\
\text { than }\end{array}$ & $\begin{array}{l}\text { Equal or } \\
\text { less than }\end{array}$ & $\begin{array}{l}\text { Equal or } \\
\text { greater } \\
\text { than }\end{array}$ & $\begin{array}{l}\text { less } \\
\text { than }\end{array}$ \\
\hline \multicolumn{7}{|l|}{ Anthracite } \\
\hline 1. Meta-anthracite & 98 & - & - & 2 & - & - \\
\hline 2. Anthracite & 92 & 98 & 2 & 8 & - & - \\
\hline 3. Semi-anthracite & 86 & 92 & 8 & 14 & - & - \\
\hline \multicolumn{7}{|l|}{ Bituminous } \\
\hline 1. Low volatile bituminous coal & 78 & 86 & 14 & 22 & - & - \\
\hline $\begin{array}{l}\text { 2. Medium volatile bituminous } \\
\text { coal }\end{array}$ & 69 & 78 & 22 & 31 & - & - \\
\hline $\begin{array}{l}\text { 3. High volatile A bituminous } \\
\text { coal }\end{array}$ & - & 69 & 31 & - & 14000 & - \\
\hline $\begin{array}{l}\text { 4. High volatile B bituminous } \\
\text { coal }\end{array}$ & - & - & - & - & 13000 & 14000 \\
\hline $\begin{array}{l}\text { 5. High volatile C bituminous } \\
\text { coal }\end{array}$ & - & - & - & - & 11500 & 13000 \\
\hline \multicolumn{7}{|l|}{ Sub- bituminous } \\
\hline 1. Sub- bituminous A coal & - & - & - & - & 10500 & 11500 \\
\hline 2. Sub- bituminous B coal & - & - & - & - & 9500 & 10500 \\
\hline 3. Sub- bituminous C coal & - & - & - & - & 8300 & 9500 \\
\hline \multicolumn{7}{|l|}{ Lignite } \\
\hline 1. Lignite $A$ & - & - & - & - & 6300 & 8300 \\
\hline 2. Lignite $B$ & - & - & - & - & - & 6300 \\
\hline
\end{tabular}




\subsubsection{Ash and Mineral Matter}

Coal ash is known to be the coal combustion residuals. Some byproducts of ash obtained by burning coal are fly ash, fine particles composed mostly of silica; bottom ash, angular and large ash particles; boiler slag etc.

The influence of mineral matter on the susceptibility of coal to ignite spontaneously is inconclusive because conclusions obtained in different researches can be different. A research done in Australia about the influence of inorganic matter and reactor size in SCC using Victorian brown coal showed that the presence of inherent elements like $\mathrm{Fe}, \mathrm{Mg}, \mathrm{Na}$, Si may catalyze the oxidation of coal and the conclusion is that removing the inherent inorganic matter helps to reduce the self-heating potential. Another conclusion was that after applied the additives $\mathrm{FeS}_{2}, \mathrm{CaCO}_{3}, \mathrm{KAc}$ and $\mathrm{NaAc}$, the susceptibility to spontaneous of the acid- washed coal increase (Wiwik and Dong 1998).

On the other hand, Beamish and Blazak found a negative correlation between ash and the $R_{70}$ self-heating rate of subbituminous coal. The following equation shows the $R_{70}$ as a function of ash percentage:

$$
R 70=0.0029 * a s h^{2}-0.4889^{*} a s h+20.644
$$

The results of the experiments such as the pronounced delay of high ash content coal reaching the thermal runway in $\mathrm{R}_{70}$ drove them to the conclusion that the mineral matter in the coal acts like a heat sink (Beamish and Blazak, 2005).

\subsubsection{Volatile Matter}

Volatile matter in coal is the component of coal, except for moisture, which are liberated at high temperature in the absence of air. This is a mixture 
of short and long hydrocarbon chain, aromatic hydrocarbon and some sulfur. In this research, the proximate analysis and it will be possible to see that the volatile matter is liberated at around $900{ }^{\circ} \mathrm{C}$.

A research conducted in Turkey using 119 samples from Zonguldark coal region, also in Turkey, used the results of linear and multiple regression analyses to determine the relationship between SCC and coal parameters such as obtained from proximate, ultimate and petrographic analysis. An important conclusion was that ash, volatile matter, carbon content, mineral matter and a few other coal components play a major factor on SCC susceptibility. To focus on this topic, the volatile matter content exhibit a positive proportionality with the parameters AHR (average heating rate) and negative proportionality with the CPT (crossing point temperature) (Kaymakci and Didari, 2000), see the equations obtained:

$$
\begin{aligned}
& \text { AHR }=0.47+0.06 \mathrm{~N}+0.04 \mathrm{H}+0.006 \mathrm{VM}+0.02 \mathrm{I}-0.08 \mathrm{~S}-0.004 \mathrm{O}-0.002 \mathrm{C} \\
& \mathrm{CPT}=227.09-7.61 \mathrm{~N}-1.29 \mathrm{H}-0.87 \mathrm{VM}-0.9 \mathrm{I}-1.23 \mathrm{~S}+0.33 \mathrm{O}-0.04 \mathrm{C}(2.4)
\end{aligned}
$$

Since all the samples were obtained from the same region, it is senseless to use this regression to find parameters from different regions but the same linear regression can be done using the same methodology. 


\section{Experiments}

\subsection{Adiabatic method to evaluate $\mathbf{R}_{70}$}

The $R_{70}$ test provides a quick measurement of the intrinsic reactivity of coal to oxygen and is backed by an extensive database of results from locations around the world. The $\mathrm{R}_{70}$ depends on coal rank and are affected by the intrinsic properties of the coal type. The RIT value (Relative Ignition Temperature) of each sample, is also used to confirm the intrinsic spontaneous combustion reactivity of the coal. To understand the influence of the humidity in the air to the SCC potential, it will be found three $\mathrm{R}_{70}$ to each sample; one using inflow of dry oxygen, one using approximately $17.31 \mathrm{~g} / \mathrm{m}^{3}$ (absolute humidity at $20^{\circ} \mathrm{C}$ ) of water vapor. See in the figure 5 an example of the determination of $\mathrm{R}_{70}$;

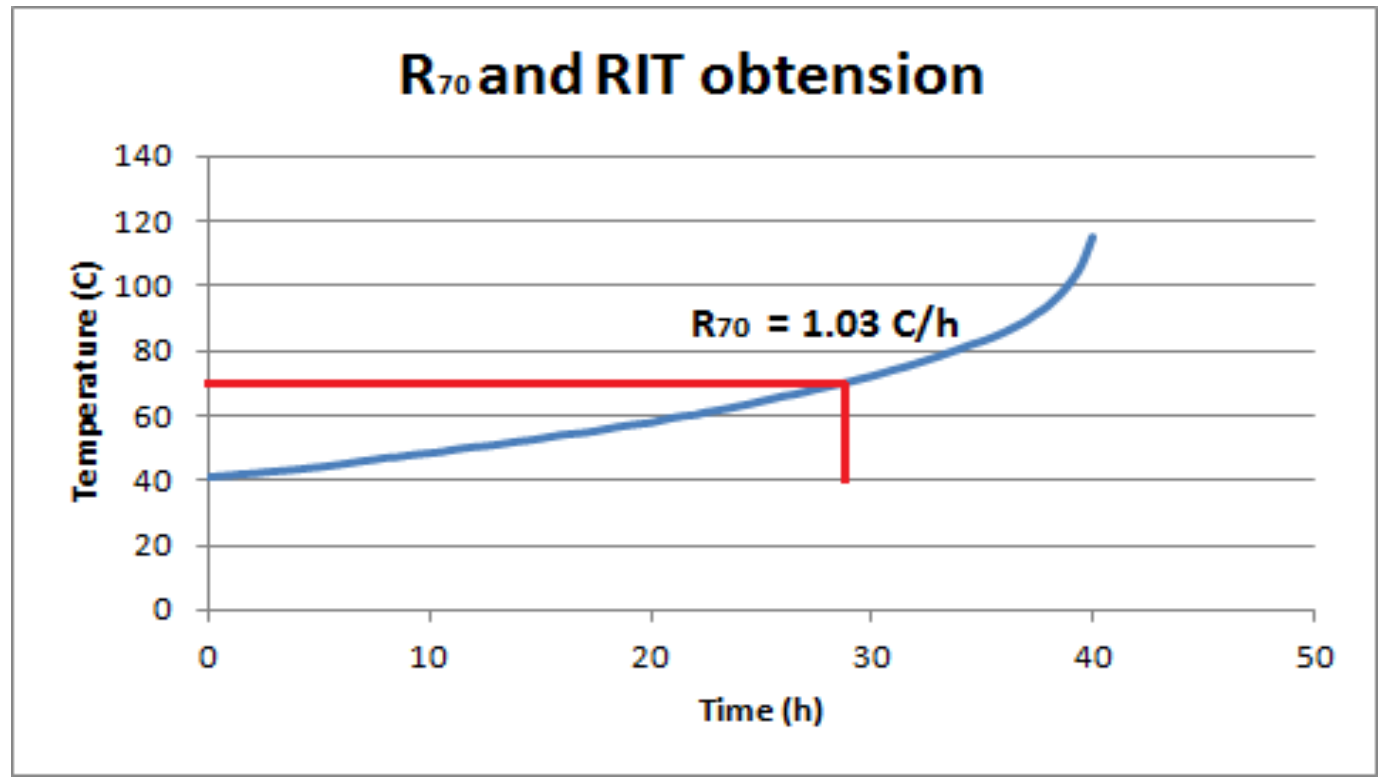

Figure 5-Obtainment of $R 70$ using coal from South America.

The $\mathrm{R}_{70}$ and RIT are obtained using the adiabatic oxidation method.

Since it is possible to obtain the temperature as a function of time in a temperature range between $40^{\circ} \mathrm{C}$ and $200^{\circ} \mathrm{C}$, this method is good to analyze 
the process of oxidation and heat storage at low temperatures. The experiment to obtain this parameters uses a reaction vessel, adiabatic oven, dry oxygen flow to the inside the vessel and a thermometer. It is very important that the heat generated by the reaction occurring inside the vessel, between the coal and oxygen, be used only to heat up the coal, in other words, heat exchange between the vessel and the environment or from the coal to the inflow of oxygen must be avoided. That's why the vessel is let inside a temperature controlled oven; the oven temperature must be at the same temperature as the coal`s temperature and the oxygen, before getting into the vessel, passes through a heat exchange located inside the oven.

Indeed the standard experiment is done using a flow of dry oxygen but we know that in reality the air has moisture in its composition. It was shown previously that the environment humidity and water content in coal affect the spontaneous combustion susceptibility. Therefore three different adiabatic experiments will be done with each sample to see how the differences of $R_{70}$ obtained.

Table 2 shows interpretations of different values of $R_{70}$.

Table 2- R70 Index

\begin{tabular}{|l|l|}
\hline Range of R70 & Classification \\
\hline $\mathrm{R}_{70}<1.0^{\circ} \mathrm{C} / \mathrm{h}$ & Low \\
\hline $1.0<\mathrm{R}_{70}<2.0^{\circ} \mathrm{C} / \mathrm{h}$ & Low-medium \\
\hline $2.0<\mathrm{R}_{70}<4.0^{\circ} \mathrm{C} / \mathrm{h}$ & Medium \\
\hline $4.0<\mathrm{R}_{70}<8.0^{\circ} \mathrm{C} / \mathrm{h}$ & High \\
\hline $8.0<\mathrm{R}_{70}<16.0^{\circ} \mathrm{C} / \mathrm{h}$ & Very high \\
\hline $16.0<\mathrm{R}_{70}<32.0^{\circ} \mathrm{C} / \mathrm{h} \mathrm{h}$ & Ultra-high \\
\hline$>32^{\circ} \mathrm{C} / \mathrm{h}$ & Extremely high \\
\hline
\end{tabular}




\subsubsection{Sample Collection}

The intention of this research was to find the spontaneous combustion propensity of the main coal reserves of South America. Despite of efforts to obtain coal samples from several places, Cerrejón was the only company able to do it but Companhia Riograndense de Mineração, a Brazilian coal mining company provided important data necessary to calculate parameters that measures the propensity of spontaneous combustion of coal.

The coal samples were obtained from Cerrejón mining company located in La Guajira, Colombia where it produces 32 million tons of thermal coal a year. The relevance of these samples comes from the fact that they came from the biggest coal operation and reserve of Latin-America, and the tenth biggest coal mine in the world. Furthermore they represent Colombia, ninth biggest coal reserve in the world and biggest in Latin America.

The coal samples obtained were prepared to mesh $4(4.75 \mathrm{~mm}$ nominal size) and about $5 \mathrm{~kg}$ each. Coal loaded onto every vessel is sampled by an automatic sampling system working according to ASTM standards and proven to be bias free. The primary cutter takes an increment every 26 seconds of coal as it is (normally 2 " or $50 \mathrm{~mm}$ nominal top size) and the coal is conveyed through a system where secondary cutter takes at least six increments from each primary increment and then the size of the sample collected by the secondary cutter is crushed by a crusher to mesh 4 and taken to a tertiary cutter where about one increment is taken from each secondary increment. This means that for each for each 10,000 tons lot, the sampling system delivers about $80 \mathrm{~kg}$ of a final save to mesh No. 4. This sample is taken to a preparation room where the total amount is homogenized and riffled to obtain 4 to 6 splits which are 
distributed as follows: one to be used by the laboratory for analysis, one for coal buyer, one for Cerrejón(coal seller), one as referee sample in case of a challenge to the official results, and two to be kept as reserve samples for special cases. One special case is this research. As Cerrejón loaded coal of different coal grades, it was selected those cargoes whose final results were closer to the typical values of Cerrejon different coal grades, and they were sent to West Virginia for studies. Finally the coal samples type studied were D, DM, E and $\mathrm{C}$.

The data obtained from the Brazilian coal miner are important because they represent the material from the biggest coal producer in that country, also representing the biggest coal operation. The Companhia Riograndense de Mineração produced in 2014 approximately 3.5 million tons of thermo coal. Their operations are located one in Candiota County and other two in Minas do Leão County, all of them located in Rio Grande do Sul State, south region of Brazil. Figure 6 shows the map with the locations where the mines quoted are located.

\subsubsection{Binider FD 53}

Binder FD 53 is a heating oven used when fast drying and sterilization is required. This oven has in it a fully homogeneous temperature distribution, quick dynamics and powerful fan. See the oven and its specifications (for more information visit the website binder-oven.com). 


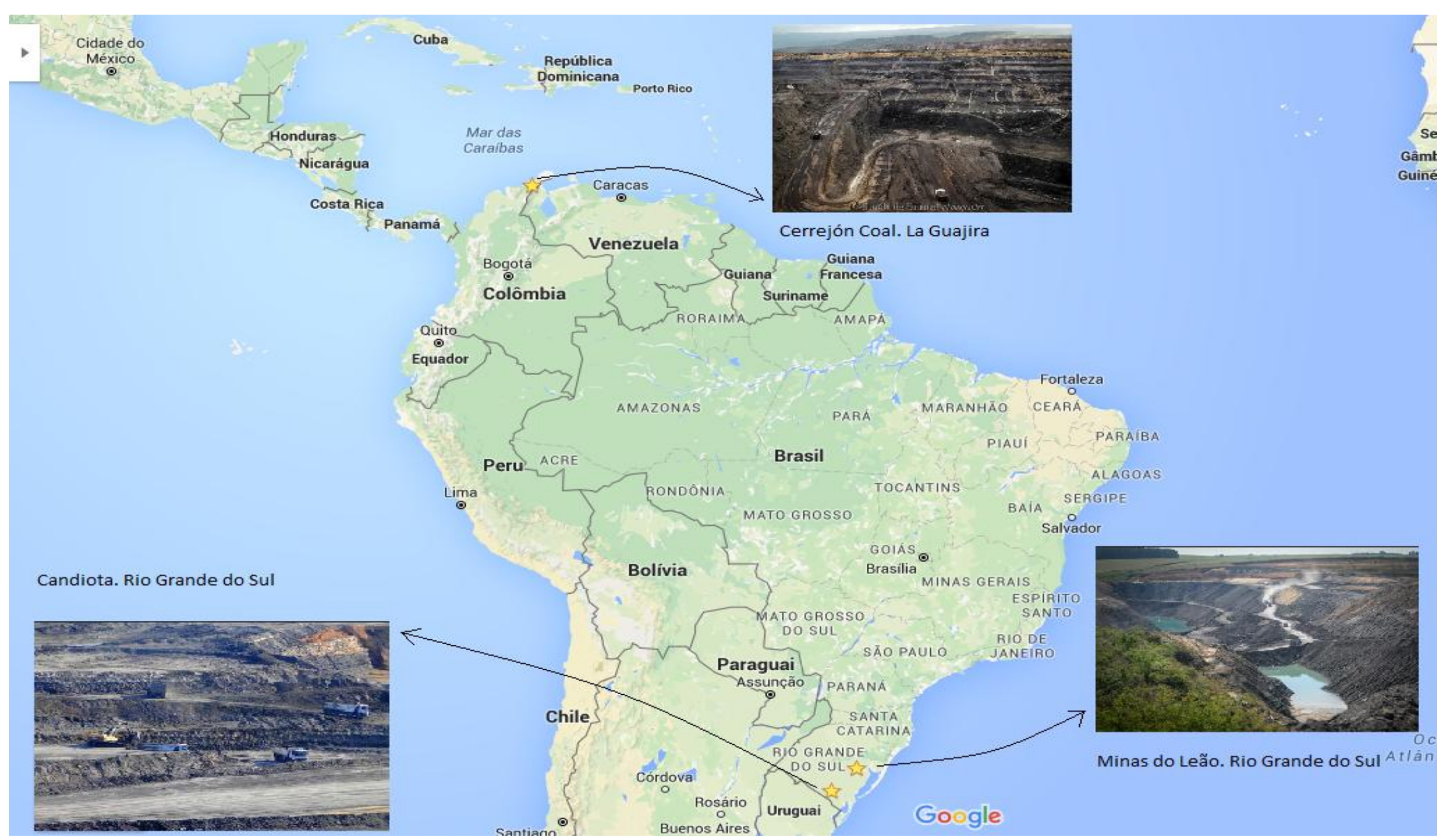

Figure 6-Cerrejón and CRM Coal Mine Locations 


\subsubsection{Instruments}

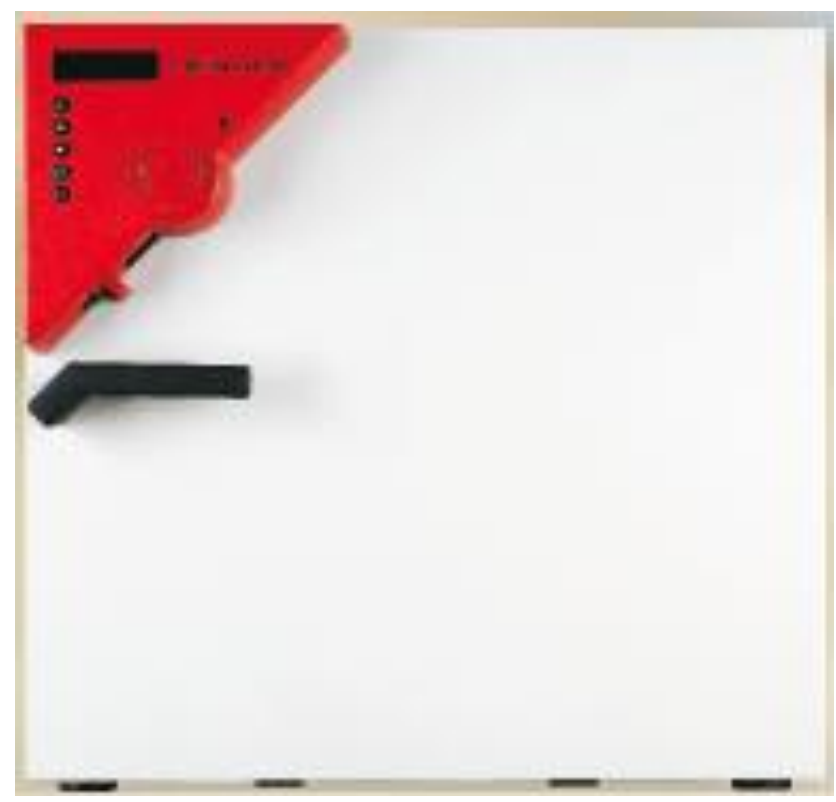

Figure 7-Binder FD 53

Table 312 Binder FD-53 dimensions

\begin{tabular}{|l|r|}
\hline Exterior Dimensions & Values \\
\hline Width (mm) & 635 \\
\hline Height & 620 \\
\hline Depth (plus connections and fittings) & 575 \\
\hline Depth (incl. connections and fittings) & 690 \\
\hline Interior Dimensions & \\
\hline Width (mm) & 400 \\
\hline Height & 400 \\
\hline Depth & 340 \\
\hline Interior Volume (I) & 53 \\
\hline
\end{tabular}

\subsubsection{Reaction Vessel}

The reaction vessel is a $473 \mathrm{ml}$ aluminum thermo-bottle that is fitted with

a rubber plug for sealing. Inside the reaction vessel the reaction between oxygen and coal so the function of the reaction vessel is to keep the coal, receive oxygen flow and avoid heat exchange between the coal and the oven. Two cupper tubes pass through the rubble plug. One tube for the inlet flow of 
oxygen and nitrogen and other for the outlet flow of product gases like $\mathrm{CO}, \mathrm{CO}_{2}$, $\mathrm{H}_{2} \mathrm{O}_{v}$.

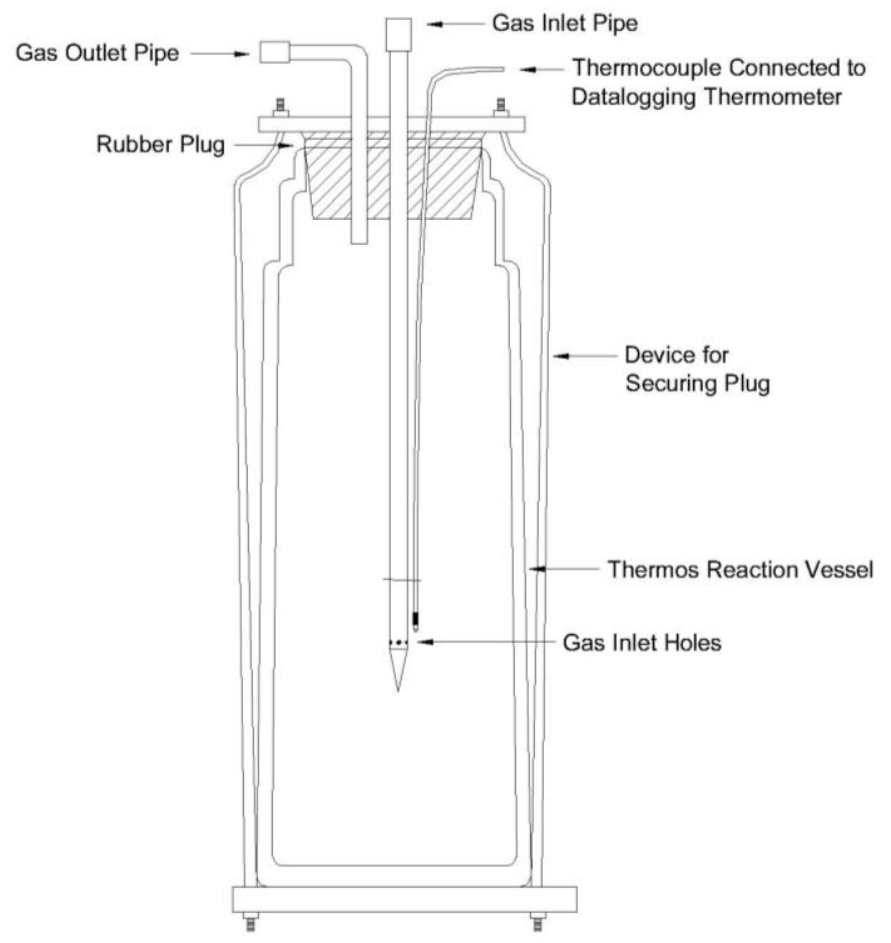

Figure 8-Reaction Vessel

The gas inlet holes are where the inlet gases pass through to get in contact with coal. The device for securing plug avoids gas leak and finally the rubber plug seal the reaction vessel.

\subsubsection{Coil Copper Tubing}

For the inlet and outlet of gas, 20 feet copper tube with 3/8 inch inner diameter was used. The copper tubing wounds in a coil to minimize temperature difference between inlet gas and oven, another important characteristic of the copper tube is that it has high thermos conductivity $(k)$ which also permits a quick heat exchange between inlet gas and the oven.

The copper tube was also used as air flow path with one end connected with the oxygen or nitrogen cylinder and the other end connected with longer 
pipe in the vessel. Another shorter tube was used to exhaust the gaseous products of the reaction that occurs in the vessel.

\subsubsection{Thermoanemometer}

The Extech thermocouple is used to measure the temperature inside the oven and of the coal inside the reaction vessel by using two thermocouples. This measurement is useful to control manually the temperature inside the oven keeping it at the same temperature as the reaction vessel's, thus avoiding heat exchange.

The temperatures measured will be transferred from the extech equipment to a computer. This computer will register in the temperature inside the reaction vessel (coal temperature), inside the oven in a pace defined by the user (every 20 minutes for example) and will calculate the difference between these two temperatures. The temperature difference can be used to calculate the heat exchange between the oven and vessel and the points of temperature as a function of time will be used to build the curve that will be used to calculate $\mathrm{R}_{70}$.

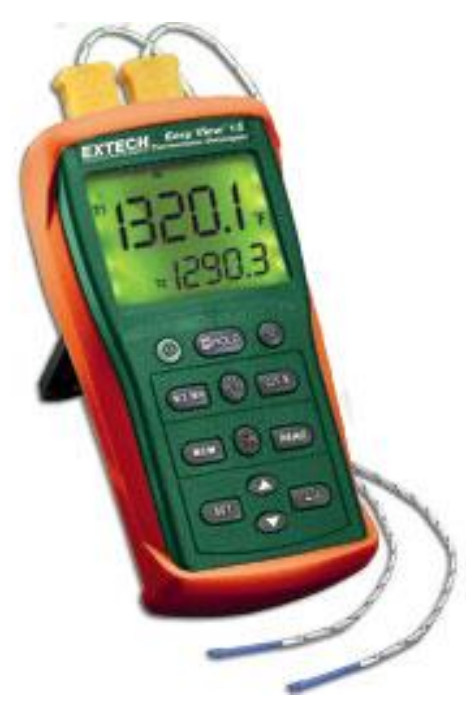

Figure 9-Extech thermocouple datalog thermometer 


\subsubsection{Experimental Procedures}

\subsubsection{Experimental Procedures of the $R_{70}$ Test}

In this experiment, approximately $150 \mathrm{~g}$ of coal of size smaller than $210 \mu \mathrm{m}$ is dried at $110^{\circ} \mathrm{C}$ under high purity nitrogen at $40 \mathrm{~mL} / \mathrm{min}$. After these 16 hours, the coal is cooled down to $40^{\circ} \mathrm{C}$ under nitrogen atmosphere. As soon as the temperature of the coal reaches $40^{\circ} \mathrm{C}$, the vessel is connected to the oxygen cylinder at the rate of $50 \mathrm{~mL} / \mathrm{min}$. The temperatures of the coal and oven will be monitored so we can get the $\mathrm{R}_{70}$ value.

\subsubsection{Experimental Procedures of Moist $R_{70}$ Test}

In the moist $\mathrm{R}_{70}$ test, the same procedure was done comparing to the dry $\mathrm{R}_{70}$ but the only difference was that the inflow of oxygen, before gets into the reaction vessel, I passes through a vacuum trap with water. This modification from previous testing procedure could enable the test to investigate the effect of moisture condensation during the initial stage of self-heating process.

\subsubsection{Results and Discussion}

Every samples sent from Cerrejón were experimented in a dry oxygen inflow environment and constant moisture oxygen inflow as showed below. All of the experiments in a dry oxygen inflow have a common result. According to $\mathrm{R}_{70}$ standard, if there is no apparent temperature rise within 36 hours, the coal samples can be classified to be low propensity of spontaneous combustion. See the table 2 . 


\subsubsection{Cerrejón Type E Coall Sample}

A coal sample from Cerrejón coal mine of type $E$ was tested with $R_{70}$ method. From the testing results it is found that the type E coal sample (Cer-E) had a complete self-heating curve for constant moisture oxygen in approximately 40 hours. In this condition, the coal sample reached the required temperature of $70^{\circ} \mathrm{C}$ in 29 hours, which means $R_{70}=1.03^{\circ} \mathrm{C} / \mathrm{h}$ indicating a low to medium propensity to spontaneous combustion. This result means that the vapor condensation in a dry coal surface significantly affects the propensity of the coal to spontaneous combustion.

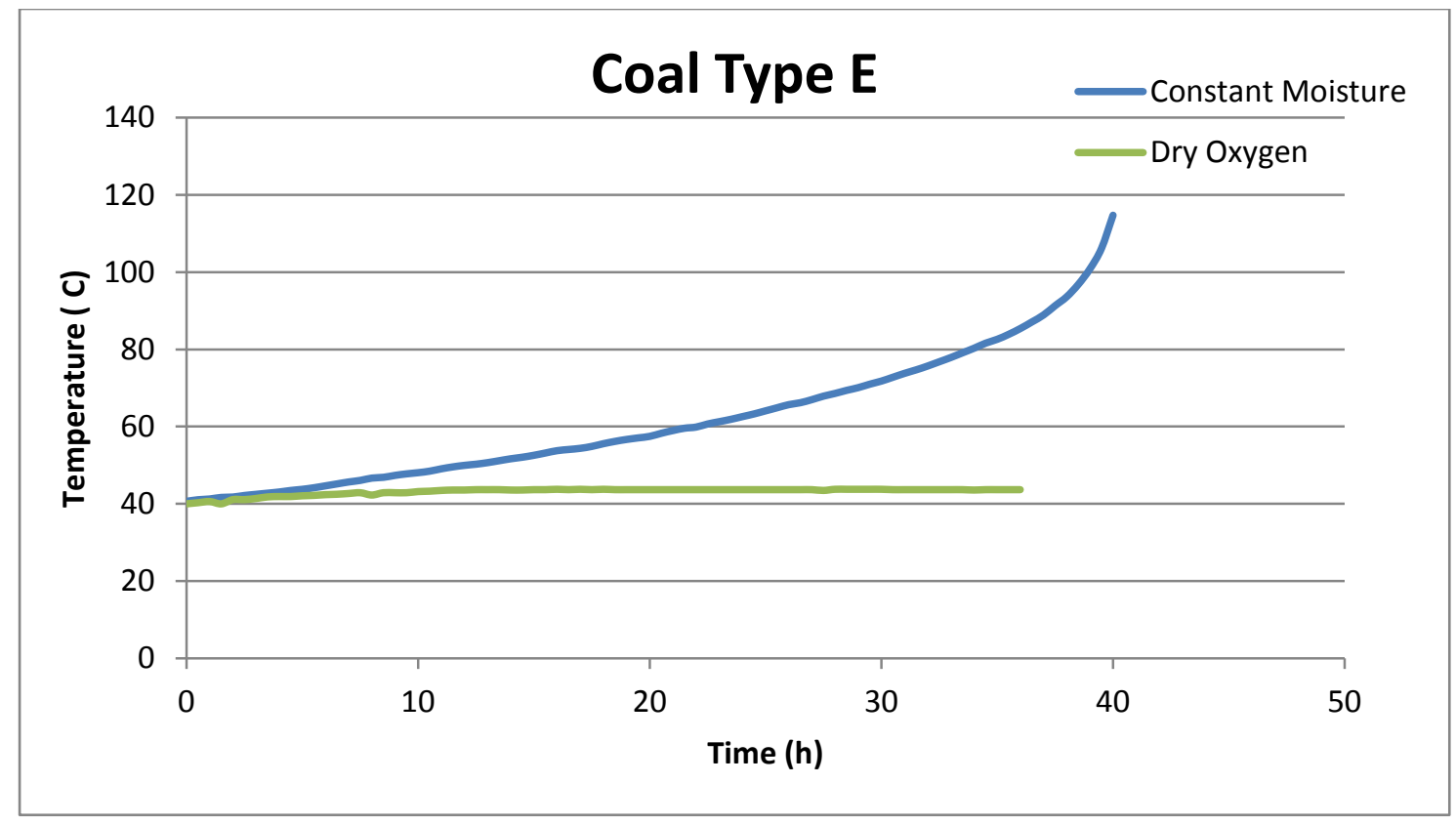

Figure 10- Cer-E Adiabatic Test Result

\subsubsection{Cerrejón Type C Coal Sample}

The Cerrejón type $\mathrm{C}$ coal (Cer-C) had a complete self-heating curve for constant moisture oxygen in approximately 25 hours. In this condition the coal sample reached the required temperature of $70^{\circ} \mathrm{C}$ in 15.5 hours resulting in $\mathrm{R}_{70}=1.94^{\circ} \mathrm{C} / \mathrm{h}$ which means a low to medium propensity to spontaneous combustion. 
Such as happened with the Cer-E, the value of $\mathrm{R}_{70}$ obtained using Cer-C had a significant variation, however, here the propensity to spontaneous combustion of coal in such condition is considerably higher.

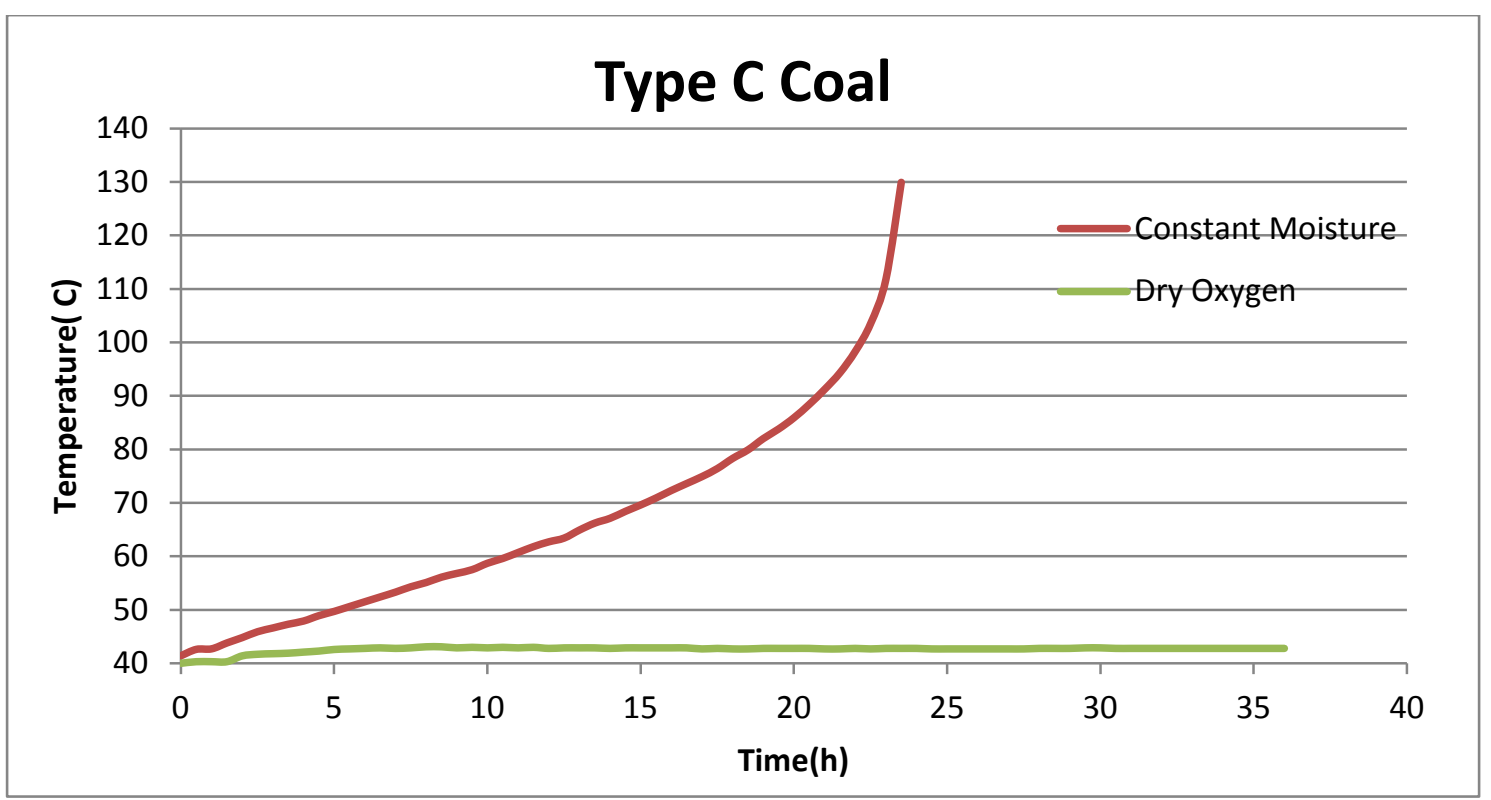

Figure 11-Cer-C Adiabatic Test Result

\subsubsection{Cerrejon Type D Coal}

Figure 12 shows the self-heating test curves for the Cerrejón type D coal showed was not tested until the obtainment of the complete self-heating curve due to the extensive time that would be required. From the result below it is possible to see that even in moist oxygen condition the coal showed a very low propensity to spontaneous combustion. Until the moment that this experiment was done, the average temperature rise rate is approximately $0.38^{\circ} \mathrm{C} / \mathrm{h}$. By far the lowest value of $R_{70}$ would be obtained in this sample.

Such difference of $\mathrm{R}_{70}$ obtained in this experiment can be explained by the aging effect; this coal sample was the last one to be experimented and 
therefore needed to spend a few days exposed to opened environment until the sieving process.

Beamish showed from several experiments that equal coal samples can result in significantly different values of $R_{70}$ if passing by aging process and he concluded that as longer is the process of aging, lower the $R_{70}$ will be (Beamish,2000).

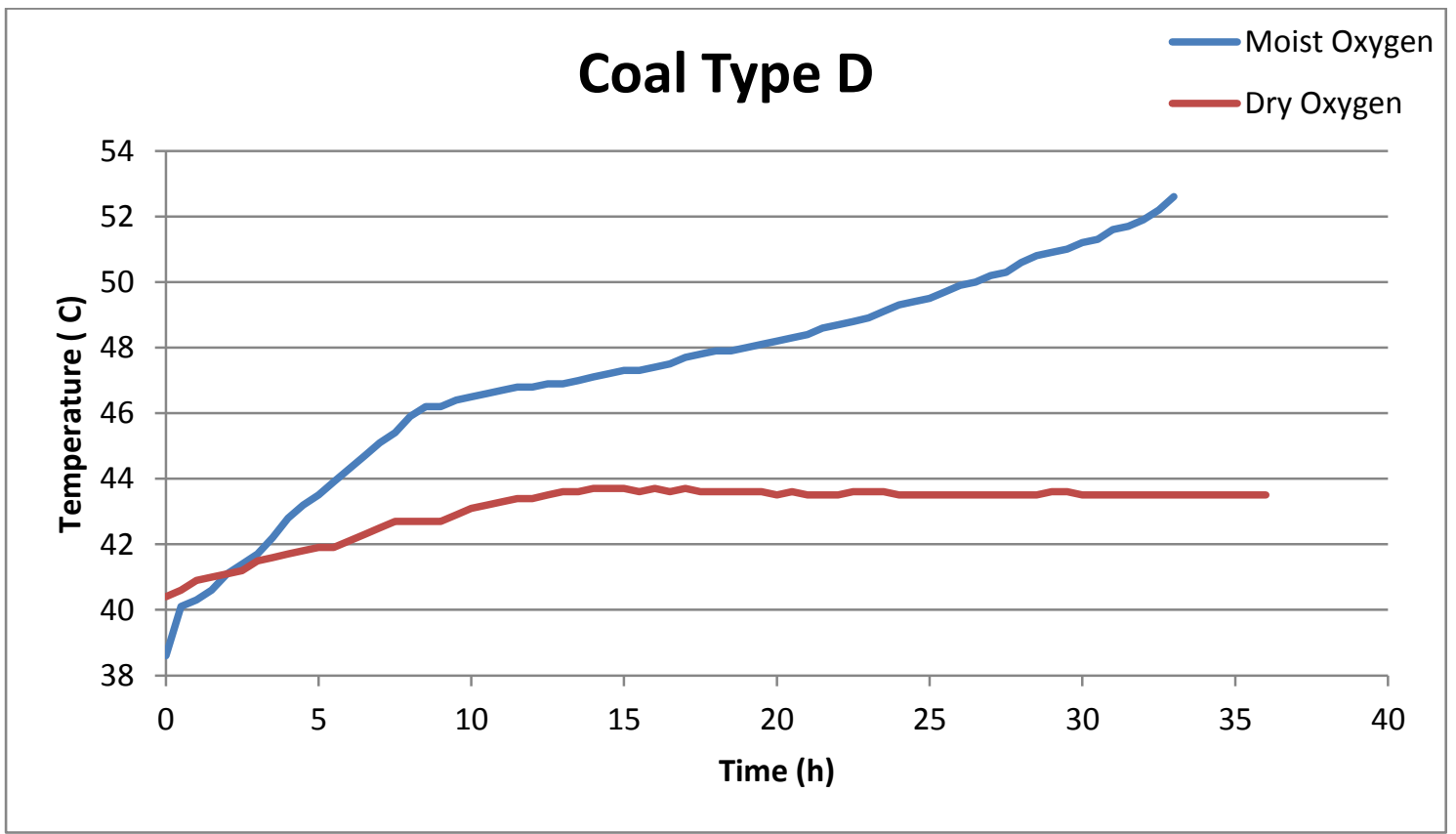

Figure 12-Cer-C Adiabatic Test Result

\subsubsection{Cerrejón Type Dm Coal}

In a constant oxygen moisture condition this experiment was done until the obtainment of $\mathrm{R}_{70}=2.26^{\circ} \mathrm{C} / \mathrm{h}$. The coal Cer-Dm demonstrated the highest propensity to spontaneous combustion among the Cerrejón coal samples in this condition. 


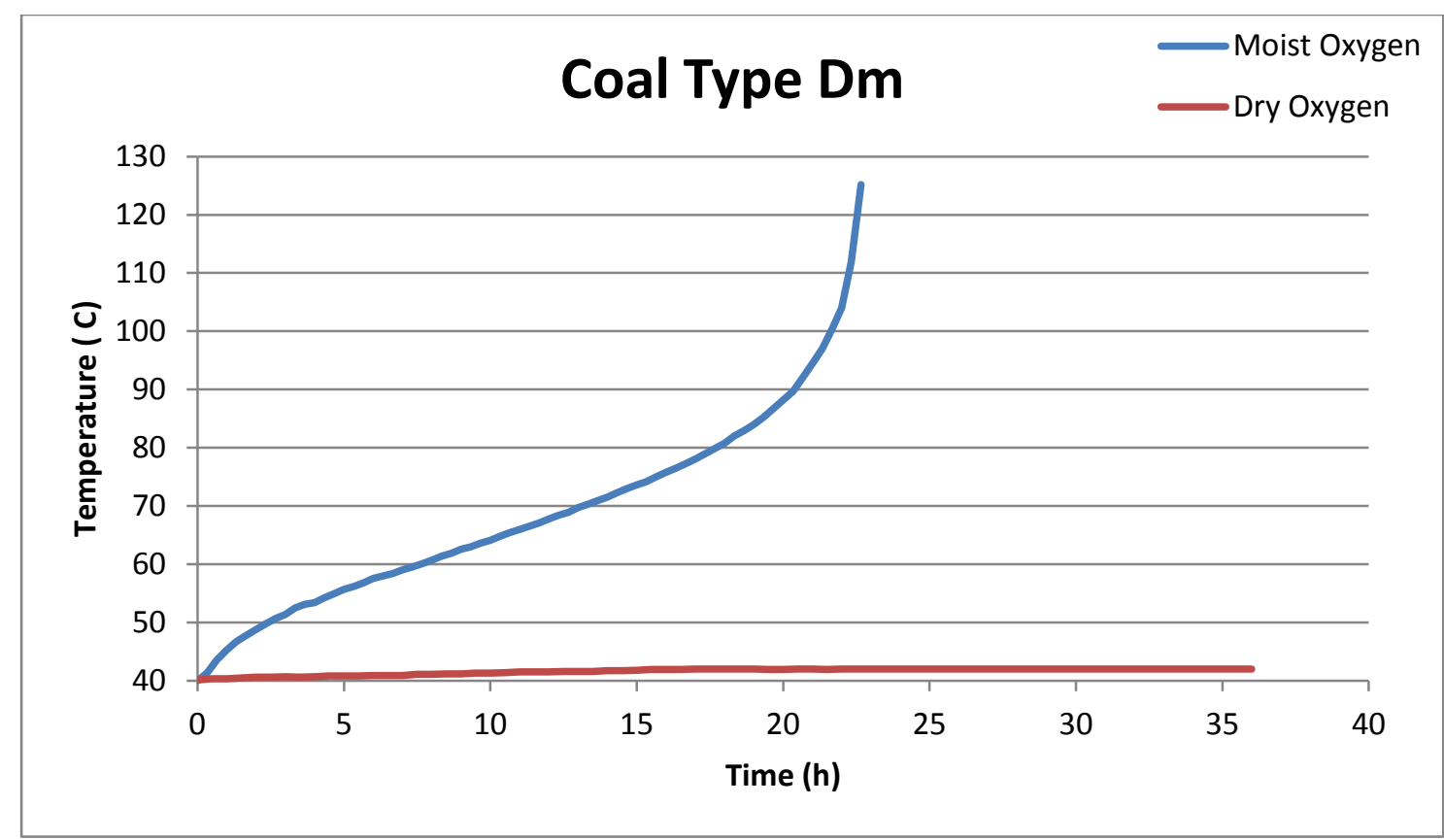

Figure 13-Cer-C Adiabatic Test Result

\subsubsection{Comparative}

It is possible to see below a chart useful to visualize the differences in the temperature rise in every coal experimented in a moist oxygen condition. See again that the order of $R_{70}$ obtained from the lowest to the highest (lowest propensity to SCC to highest propensity) is Cer-D $<$ Cer-E $<$ Cer-C $<$ Cer-Dm.

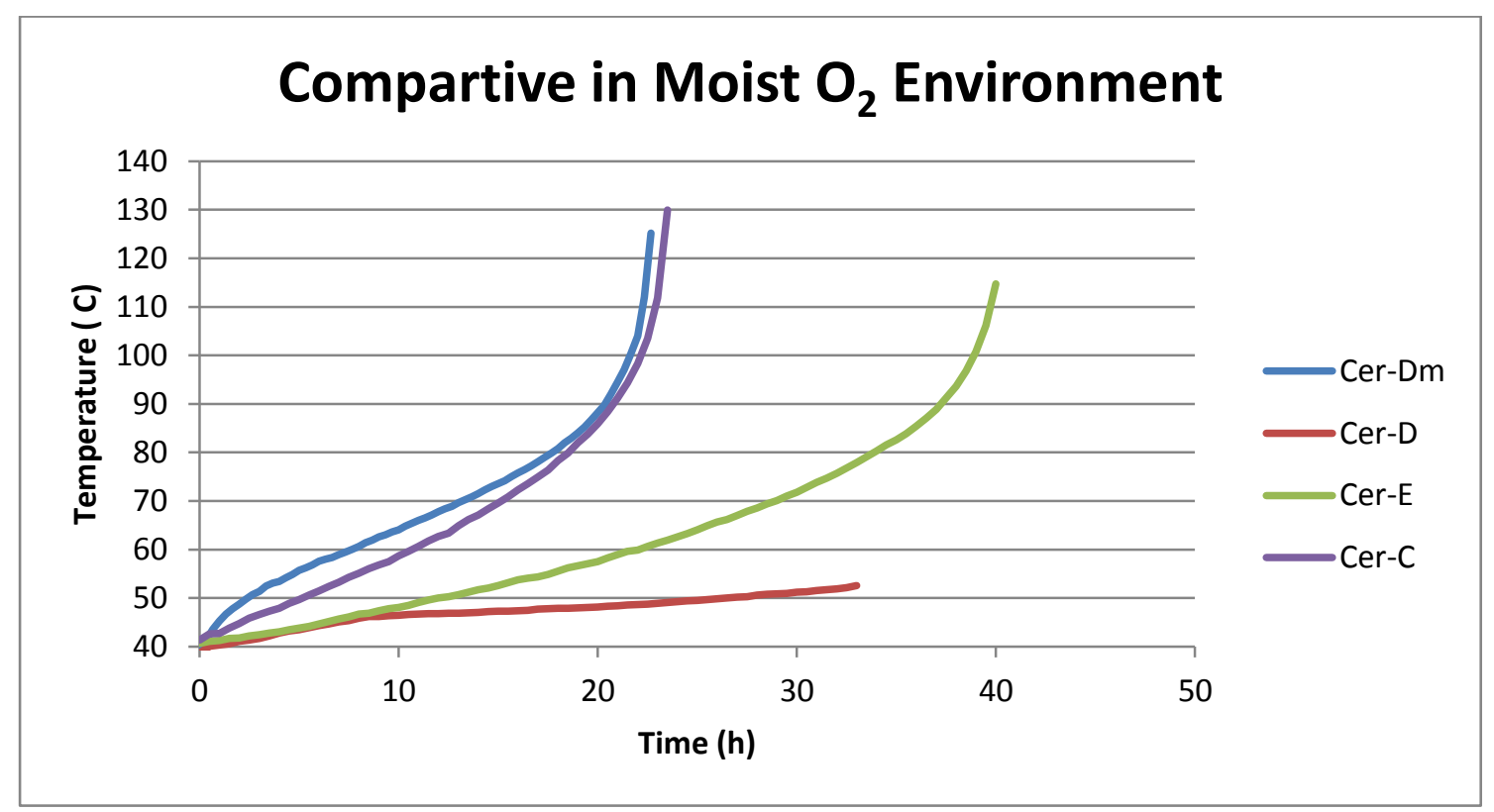

Figure 14- $R_{70}$ curves of Colombian coal samples in moist environment 


\subsection{TGA: Activation Energy Determination}

Thermogravimetry is a technique in which the mass of a substance is continuously monitored as a function of a temperature or time as the sample specimen is subjected to a controlled temperature program. Today this method is used in branches of chemistry, geology, fuel science.

The graphic presentation of the result of some experiment may be expressed as either the weight or weight percent of the original sample remaining versus temperature or time. The figure 15 shows a typical TGA curve that gives the weight percent of the original sample versus temperature for a coal collected in Cerrejón mining complex that is located nearby the municipality of Albania, between the Sierra Nevada de Santa Marta and the Serranía del Perija in La Guajira eastern region, Colombia.

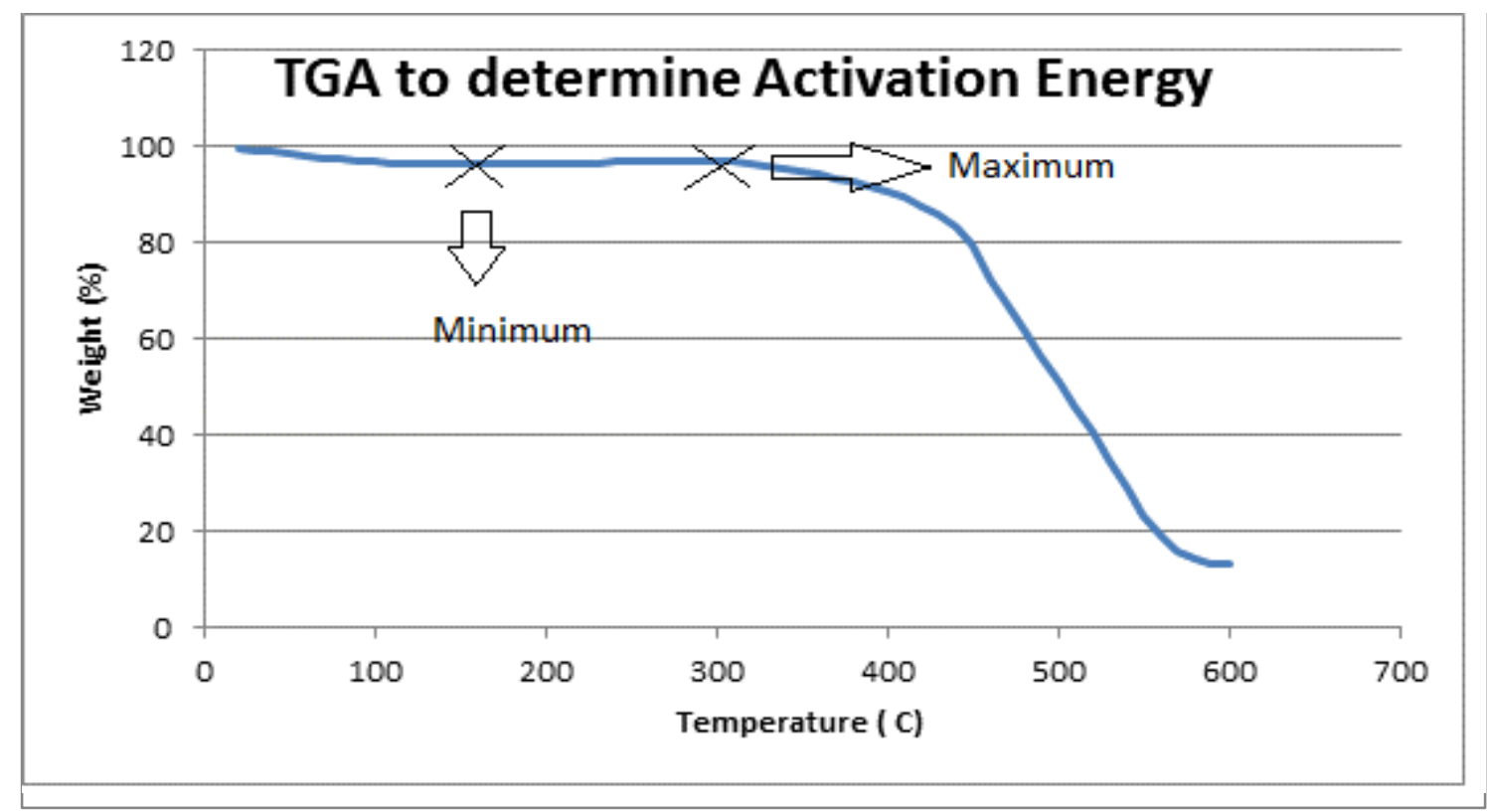

Figure 15- Weight as a function of temperature used to determine activation energy of coal

Many commercial TGA systems are available. The major difference are in furnaces, maximum balance sensitivity and the dynamic purge gas flows 
across the TG sample specimen horizontally rather than vertically (ASTM, 1988).

The activation energy determination measurement (also an indicator of spontaneous combustion propensity) as an independent kinetic parameter of a coal can be determined from a data analysis procedure of the TGA testing results. If the coal has high potential to spontaneous combustion the weight gain between the maximum and minimum tends to be high thus generating higher activation energy.

\subsubsection{Sample Collection}

The same samples that were used in the adiabatic method were used to determine the activation energy of coal. To see the description of the samples go to section 3.1.1.

\subsubsection{Instruments}

To support this dissertation the TGA equipment used was the TA Q50. In the TA Instruments words this equipment offers exceptional value as compact, general purpose thermogravimetric analyzer that typically outperforms competitive research-grade models. It has integral mass flow control, gas switching capability, superb software, and is ease-of-use.

Important features of these equipment are the presence of a furnace, temperature control and measurement by using two thermocouples, mass flow control with automatic gas switching, vertical thermobalance, horizontal purge gas system that allows purge gas to flow directly across the small sample. 


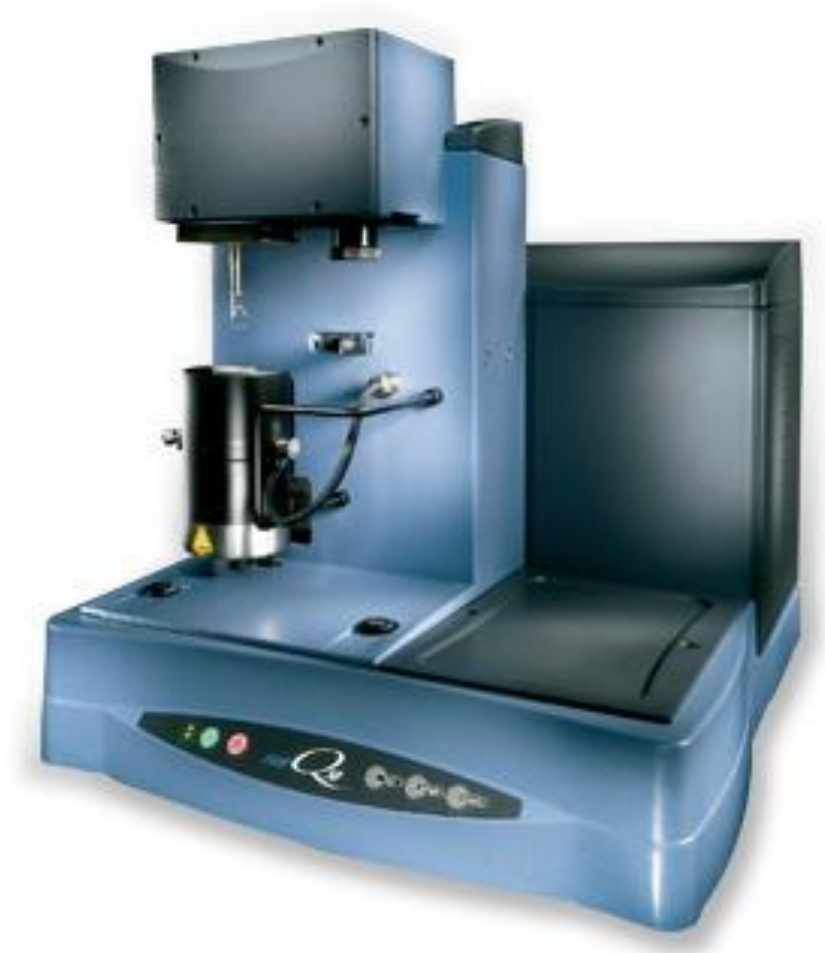

Figure 16- TGA Q50

\subsubsection{Experimental Procedures}

The samples of coal described in the topic 3.1.1 were sieved and the portion of $13-14 \mathrm{mg}$ and 50 mesh $(297 \mu \mathrm{m})$ was used in this experiment. This portion were placed in a platinum pan and loaded to a furnace. The test runs with a constant pure oxygen flow of $10 \mathrm{~mL} / \mathrm{min}$ of dry air and $40 \mathrm{~mL} / \mathrm{min}$ of high purity nitrogen passing through the coal sample. The temperature rate is precisely $+10^{\circ} \mathrm{C} / \mathrm{min}$ beginning from $18.5^{\circ} \mathrm{C}$. This process is continued until there is no more weight variation. This experiment takes approximately one hour and the weight stops changing close to $600^{\circ} \mathrm{C}$.

The weight is plotted as a function of temperature. In the initial stage the weight varies due to the loss of part of the moisture content and this stage ends in the temperature associated to the position minimum indicated in the figure 15. 


\subsubsection{How to Determine the Activation Energy}

The following linear equation was derived (Victor, 1985):

$$
\ln \left[\frac{-\ln (1-\alpha)}{T^{2}}\right]=\ln \frac{A R}{\beta E}-\frac{E}{R T}
$$

Where $\mathrm{T}$ is the temperature, $\mathrm{R}$ is the gas constant $8.314 \mathrm{~J} / \mathrm{molK}, \mathrm{A}$ is the pre exponential factor in $\mathrm{s}^{-1}, \mathrm{E}$ is the activation energy in $\mathrm{kJ} / \mathrm{mol}, \alpha$ is the fractional conversion and $\beta$ is the temperature increment rate in $\mathrm{K} / \mathrm{min}$. This equation can be seen as $y(x)=a x+b$ where $a$, the angular coefficient is $-E / R$ and the intersection of the straight line in $y$ coordinate is in $\ln (A R / \beta E)$. To determine the parameters of this equation, it is important to know the value of the temperature in the interval of maximum and minimum shown in Figure 15 and the values of $\alpha$ in every temperature and plot the figure 17 . See how to determine the value of $\alpha$ :

$$
\alpha=\frac{m_{0}-m}{m_{0}}=\frac{\Delta m}{m_{0}} \times 100 \%
$$

Where $m_{0}$ is equals to $m_{\max }-m_{\min }$ and $\Delta m$ is the difference between the weight of coal in percentage in a specific temperature and the minimum weight.

The result of the linear regression shown in the figure above gives that the angular coefficient is approximately $-1689.3=-E / R$, so the activation every $E=(8.314 * 1689.3) / 1000=14.04 \mathrm{~kJ} / \mathrm{mol}$. 


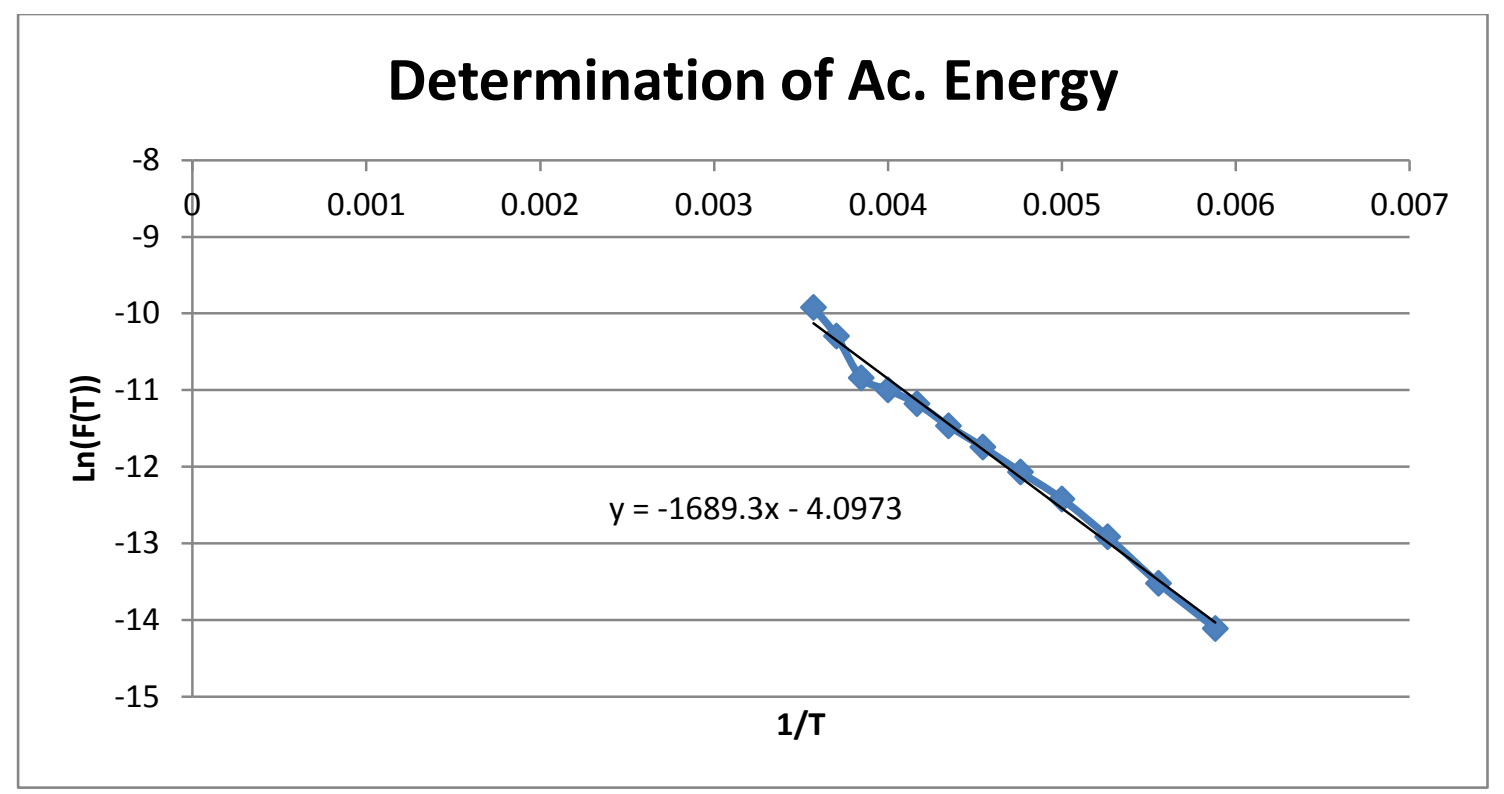

Figure 17- Regression used to determine the activation energy of coal

\subsubsection{Results}

The figures 18-21 show the TGA curves of the coal samples from Cerrejón. The two inflection points are shown in every curve as min and max and also represented in the table 5 with the respective activation energy. It was shown in Experimental and Theoretical Studies of Kinetics and Quality Parameters to Determine Spontaneous Combustion Propensity of U.S. Coals of Xinyang Wang that as higher is the activation energy, lower is the potential to spontaneous combustion of coal. The coal E experiences the highest weight variation $\Delta \mathrm{m}=0.94 \%$ between $155^{\circ} \mathrm{C}$ and $290^{\circ} \mathrm{C}$ consequently the activation energy of $E=14.04 \mathrm{~kJ} / \mathrm{mol}$.

The coal type $D$ has the lowest mass variation $\Delta \mathrm{m}=17.72 \mathrm{~kJ} / \mathrm{mol}$ between the temperatures $t_{\min }=170^{\circ} \mathrm{C}$ and $t_{\max }=280^{\circ} \mathrm{C}$ and the result of this $\mathrm{s}$ that the $D$ coal has the lowest $R_{70}$ which means the highest propensity to 
spontaneous combustion. The coal type $D$ has the highest activation energy and shows the lowest probable $\mathrm{R}_{70}$ value in a moist environment.

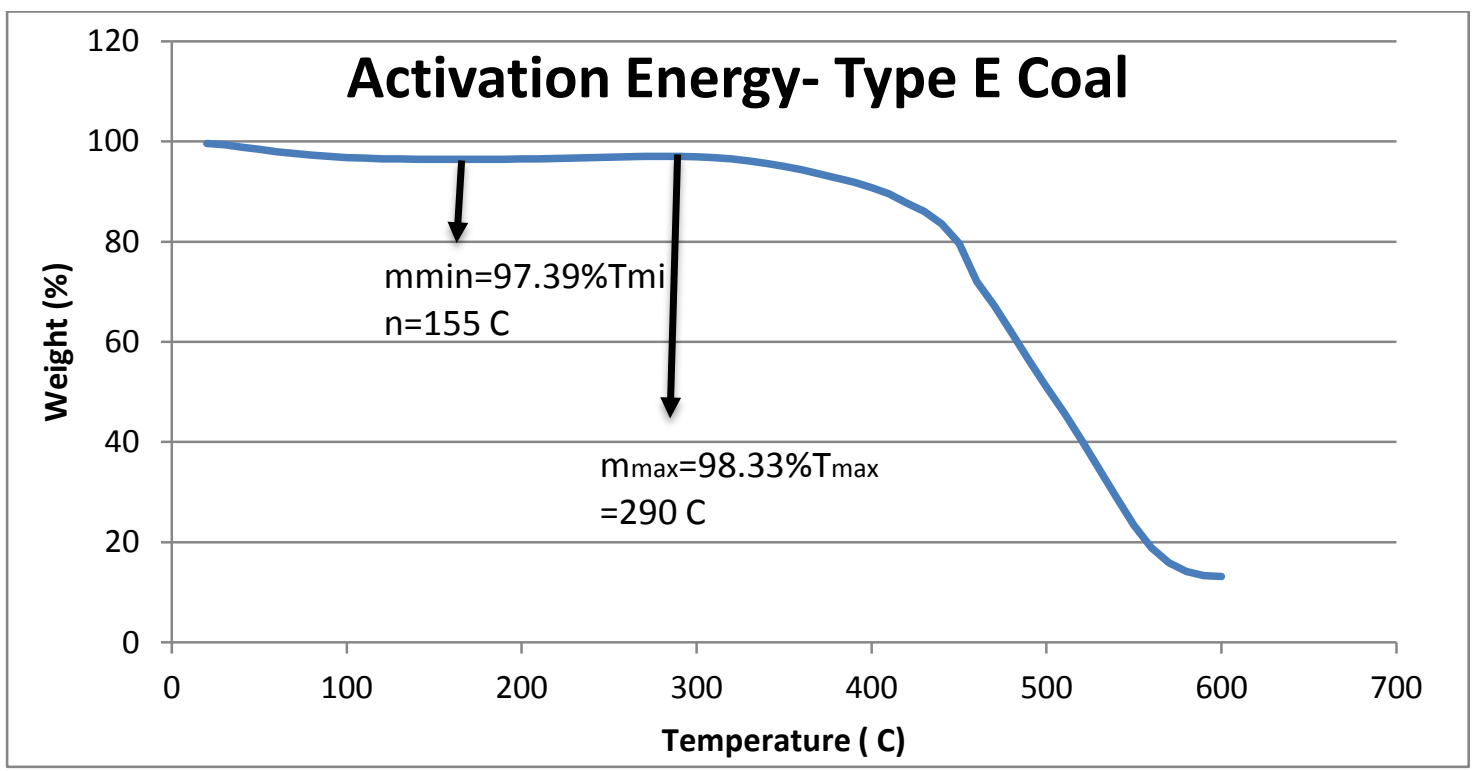

Figure 18- Weight as a function of time of coal Cer-E used to determine activation energy

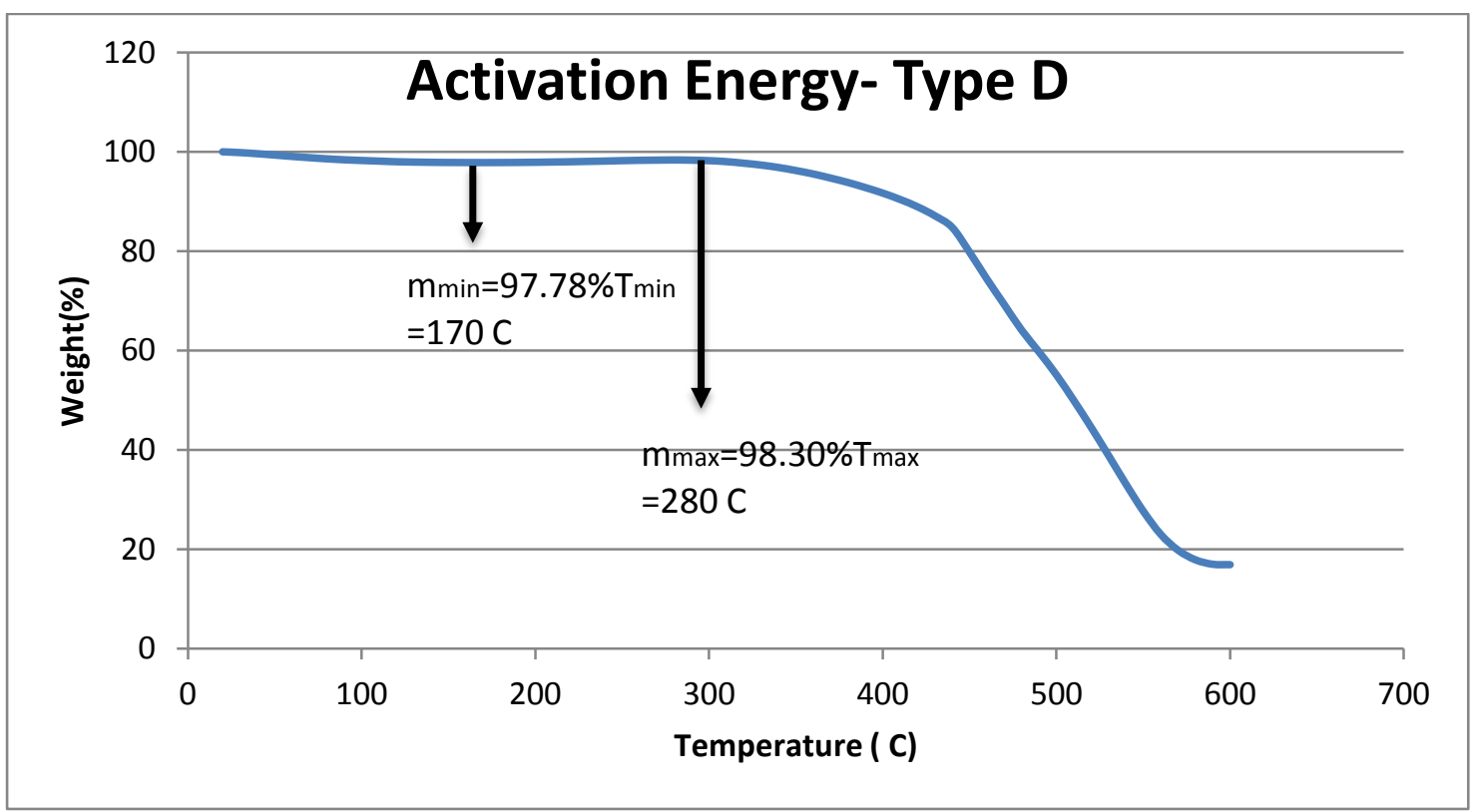

Figure 19- Weight as a function of time of coal Cer-D used to determine activation energy 
The Dm coal has the lowest activation energy and the highest value of $\mathrm{R}_{70}$ in a moist environment.

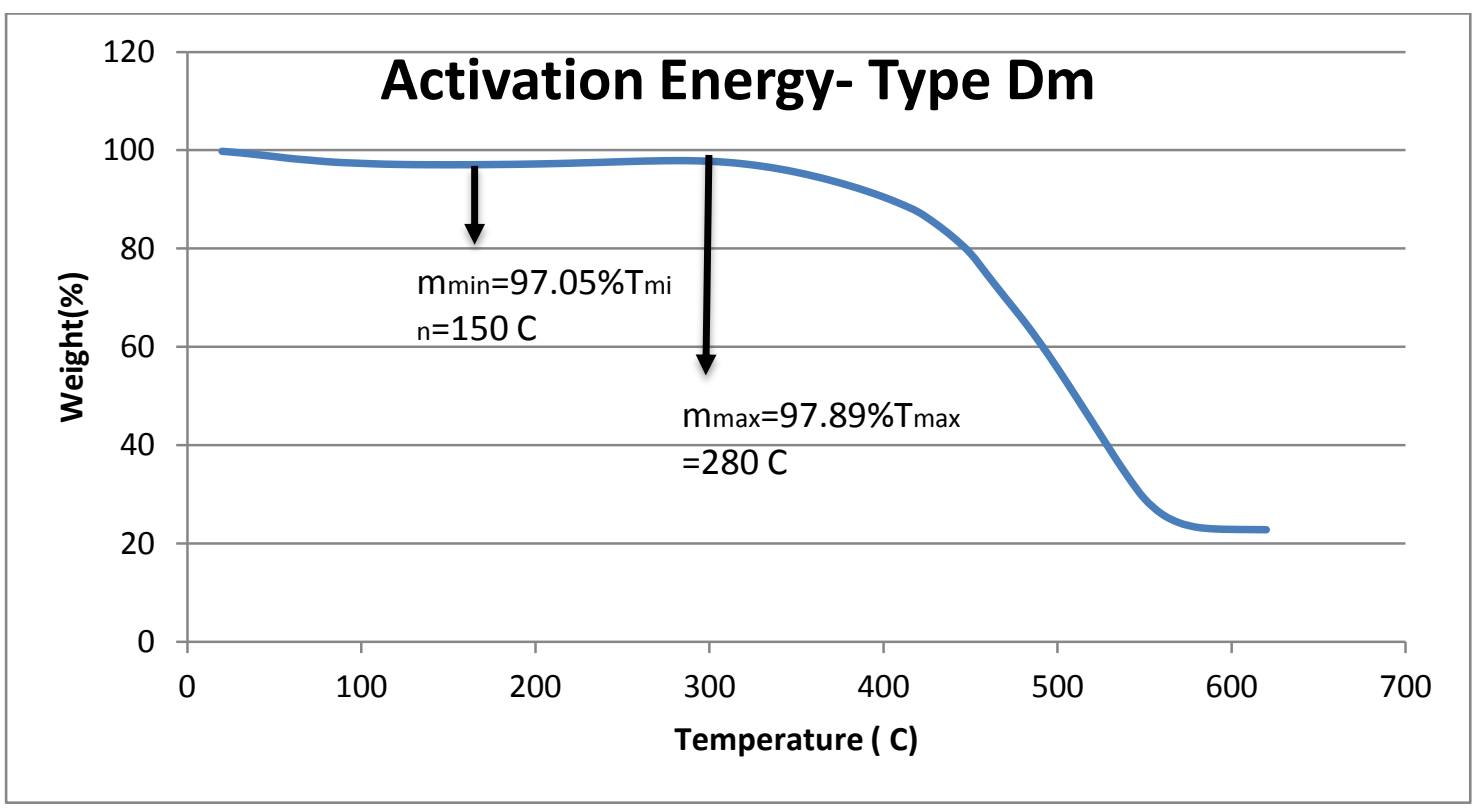

Figure 20-Weight as a function of time of coal Cer-Dm used to determine activation energy

The coal of type $C$ has activation energy higher than $E$ type but higher $\mathrm{R}_{70}$.

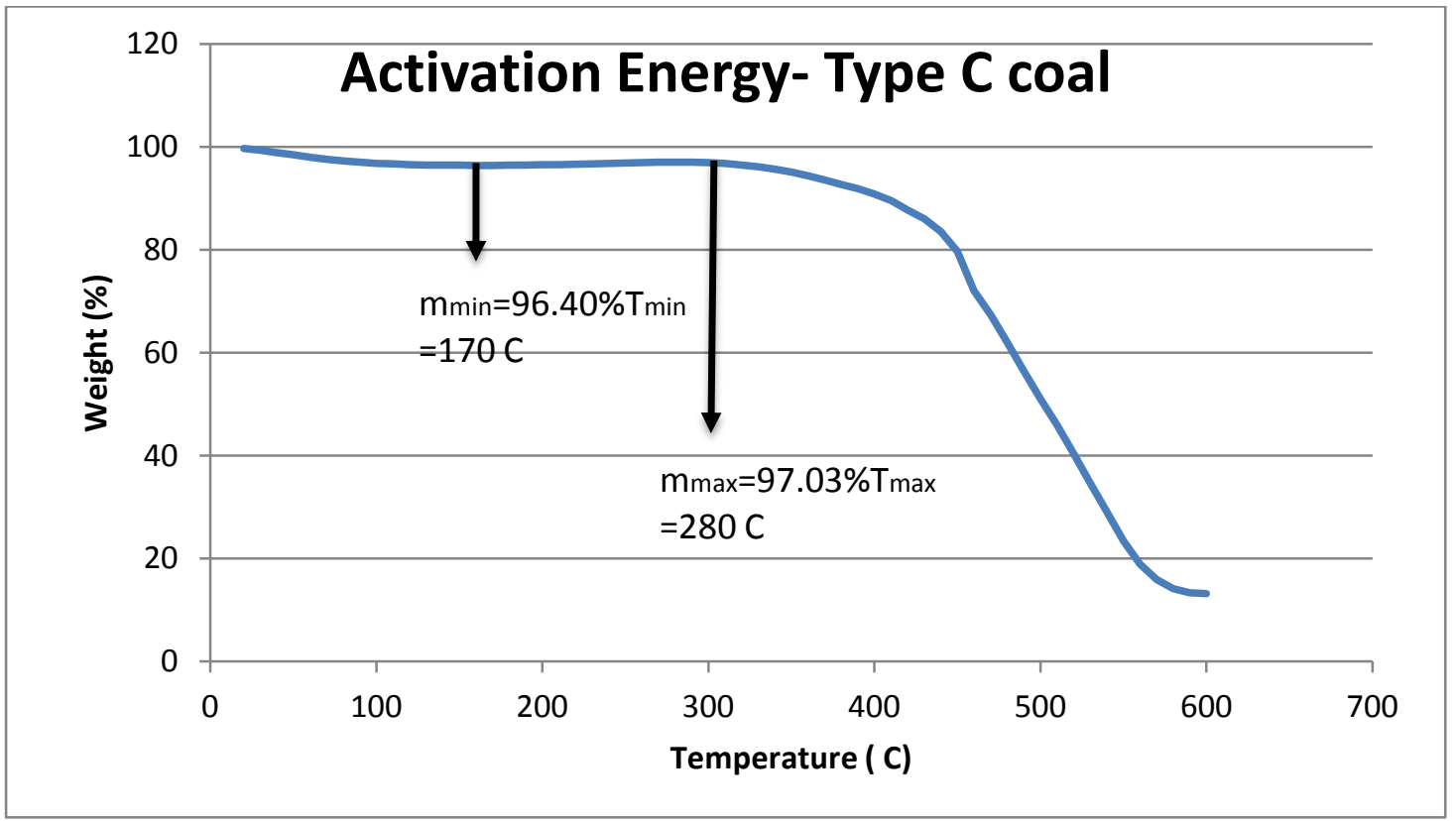

Figure 21- Weight as a function of time of coal Cer-C used to determine activation energy 
In Table 4 we can see the measurement of the parameters necessary to calculate the activation energy and the activation energy itself. It was determined previously the values of $R_{70}$. Since these values in dry oxygen and moist oxygen inflow condition are low and knowing that low activation energy represents low propensity to spontaneous combustion, it is expected that Cer-E, Cer-D, Cer-C and Cer-Dm have low values of activation energy.

To compare, Table 5 have a few values highlighted obtained from experiments done using coal samples from USA coal mines (Wang, 2014). It is possible to see that the activation energy of those coal samples are considerably higher, between $63.3 \mathrm{~kJ} / \mathrm{mol}$ and $165.9 \mathrm{~kJ} / \mathrm{mol}$ while Cerrejón coal vary between $13.5 \mathrm{~kJ} / \mathrm{mol}$ and $17,72 \mathrm{~kJ} / \mathrm{mol}$ so, unexpectedly, the values of $\mathrm{R}_{70}$ of USA coal are significantly higher than South American's coal, in the first case between $0.03^{\circ} \mathrm{C} / \mathrm{h}$ and $0.95^{\circ} \mathrm{C} / \mathrm{h}$ and in the second case, the values of $\mathrm{R}_{70}$ are so low that they are not possible to determine in a reasonable period of time. The activation energy showed to be a good parameter to compare the reactivity of the coals from Cerrejón but it is not a good parameter to compare the reactivity of very distinct coals. The conclusion here is that activation energy does not help to compare the coal propensity to spontaneous combustion of coals from different places.

Table 4 Activation Energy of Cerrejon Coal

\begin{tabular}{|c|c|c|c|c|c|c|}
\hline $\begin{array}{c}\text { Coal } \\
\text { Sample }\end{array}$ & $\mathrm{t} 1$ & $\mathrm{t} 2$ & $\mathrm{~m} 1$ & $\mathrm{~m} 2$ & $\begin{array}{c}\text { Weight Gain } \\
\% \Delta \mathrm{m}\end{array}$ & $\begin{array}{c}\text { Activation } \\
\text { Energy } \\
(\mathrm{kJ} / \mathrm{mol}) \\
\end{array}$ \\
\hline Cer-E & 155 & 290 & 97,39 & 98,33 & 0,94 & 14,04 \\
\hline Cer-D & 170 & 280 & 97,78 & 98,3 & 0,52 & 17,72 \\
\hline Cer-C & 170 & 280 & 96,4 & 97,03 & 0,63 & 15,54 \\
\hline Cer-Dm & 150 & 280 & 97,05 & 97,89 & 0,84 & 13,5 \\
\hline
\end{tabular}


Table 513 Activation energy of coals from US and China (Wang, 2014)

\begin{tabular}{|c|c|c|c|c|c|c|c|c|c|c|}
\hline \multirow[b]{2}{*}{ Coal Sample } & \multicolumn{4}{|c|}{ TGA (Wt \%) } & \multirow{2}{*}{$\begin{array}{l}\text { USBM } \\
\text { SHT } \\
(\mathrm{oC})\end{array}$} & \multirow{2}{*}{$\begin{array}{c}\text { Modified } \\
\text { SHT } \\
(\mathrm{oC})\end{array}$} & \multirow{2}{*}{$\begin{array}{c}\text { Activation } \\
\text { Energy } \\
(\mathrm{KJ} / \mathrm{mol})\end{array}$} & \multirow{2}{*}{$\begin{array}{c}\text { R70/Moist } \\
\text { (oC/h) }\end{array}$} & \multirow{2}{*}{$\begin{array}{c}\text { ASTM } \\
\text { Rank }\end{array}$} & \multirow{2}{*}{$\begin{array}{l}\text { Coal } \\
\text { Rank }\end{array}$} \\
\hline & $\begin{array}{c}\text { Moisture } \\
\text { Content }\end{array}$ & $\begin{array}{l}\text { Volatile } \\
\text { Matter }\end{array}$ & $\begin{array}{c}\text { Fixed } \\
\text { Carbon }\end{array}$ & $\begin{array}{c}\text { Ash } \\
\text { Content }\end{array}$ & & & & & & \\
\hline WR & 1.6 & 36.0 & 57.1 & 5.3 & 109 & 84.6 & 91.8 & - & $\mathrm{HvAb}$ & 12.6 \\
\hline $\mathrm{RB}$ & 1.8 & 34.5 & 42.7 & 21.0 & 98 & 82.7 & 105.0 & - & $\mathrm{HvAb}$ & 11.8 \\
\hline Sewi WV & 1.2 & 33.4 & 52.5 & 12.8 & 113 & 86.5 & 86.8 & - & $\mathrm{HvAb}$ & 12.5 \\
\hline KM3 & 9.8 & 35.3 & 48.1 & 6.8 & 35 & 43.4 & 65.9 & - & $\mathrm{HvCb}$ & 12.0 \\
\hline KM4 & 9.5 & 32.1 & 52.9 & 5.5 & 42 & 45.6 & 63.3 & 0.86 & $\mathrm{HvCb}$ & 12.0 \\
\hline Murray & 2.0 & 39.0 & 48.7 & 12.3 & 94 & 81.7 & 91.4 & - & $\mathrm{HvAb}$ & 12.4 \\
\hline Pittsburgh & 2.1 & 37.7 & 52.2 & 8.0 & 97 & 81.6 & 89.2 & 0.06 & $\mathrm{HvBb}$ & 12.2 \\
\hline Sewi GM1013 & 1.4 & 34.9 & 37.3 & 26.4 & 102 & 84.2 & 96.7 & - & $\mathrm{HvAb}$ & 11.5 \\
\hline Sewi GM1012 & 1.4 & 37.4 & 48.3 & 12.9 & 106 & 84.8 & 87.8 & 0.23 & $\mathrm{HvAb}$ & 12.0 \\
\hline FR0801 & 1.2 & 34.8 & 58.5 & 5.5 & 114 & 86.8 & 153.9 & - & $\mathrm{HvAb}$ & 13.8 \\
\hline FR0802 & 1.1 & 39.3 & 52.5 & 7.1 & 112 & 86.4 & 165.9 & 0.06 & $\mathrm{HvAb}$ & 13.4 \\
\hline FR0803 & 1.5 & 40.0 & 52.2 & 6.3 & 104 & 84.3 & 125.3 & - & $\mathrm{HvAb}$ & 13.1 \\
\hline FR0804 & 1.5 & 40.0 & 52.6 & 5.9 & 105 & 84.4 & 123.9 & - & $\mathrm{HvAb}$ & 13.2 \\
\hline FR0809 & 1.4 & 32.4 & 58.9 & 7.3 & 113 & 86.2 & 124.6 & 0.03 & $\mathrm{HvAb}$ & 13.9 \\
\hline FR0910 & 1.4 & 36.1 & 56.5 & 6.0 & 111 & 85.5 & 138.2 & - & $\mathrm{HvAb}$ & 13.5 \\
\hline FR0913/14 & 1.5 & 39.4 & 53.2 & 5.9 & 105 & 84.5 & 120.4 & - & $\mathrm{HvAb}$ & 13.3 \\
\hline PRB & 25.9 & 37.7 & 31.9 & 4.5 & 9.5 & 29.4 & 148.6 & $0.29 / 15$ & SubA & 10.1 \\
\hline SPE & 13.2 & 44.2 & 38.4 & 4.2 & 18.4 & 29.3 & - & - & $\mathrm{HvCb}$ & 10.6 \\
\hline Trapper & 11.2 & 33.5 & 43.1 & 12.2 & 30.2 & 30.0 & - & - & $\mathrm{HvCb}$ & 11.4 \\
\hline New Elk & 1.9 & 27.4 & 38.8 & 31.9 & 100.1 & 82.7 & 84.0 & - & $\mathrm{HvAb}$ & 12.1 \\
\hline $\mathrm{BBCC}$ & 18.9 & 49.8 & 26.9 & 4.4 & 8.5 & 19.2 & - & $-/ 20$ & SubA & 8.8 \\
\hline Suancigou No.4 & 4.4 & 34.0 & 39.8 & 21.8 & 58.4 & 69.6 & 84.7 & $0.95 / 1.18$ & $\mathrm{HvBb}$ & 11.3 \\
\hline Suancigou No.6 & 3.5 & 19.4 & 28.1 & 49.0 & 77.1 & 74.8 & 83.1 & - & $\mathrm{HvBb}$ & 11.4 \\
\hline Nanyangpo No.3 & 3.2 & 26.7 & 47.5 & 22.6 & 89.4 & 77.2 & 90.1 & - & $\mathrm{HvBb}$ & 12.0 \\
\hline Nanyangpo No.4 & 3.4 & 32.1 & 49.5 & 15.0 & 81.1 & 75.6 & 85.6 & - & $\mathrm{HvBb}$ & 12.2 \\
\hline Xuandong No.3 & 1.2 & 29.3 & 53.1 & 16.4 & 114.7 & 87.2 & 89.6 & - & $\mathrm{HvAb}$ & 12.1 \\
\hline
\end{tabular}

\subsection{Coal Quality Parameters}

\subsubsection{Introduction}

The proximate analysis, as explained before, gives the values of parameters such as moisture, fixed carbon, ash, moisture. Previous works were done intending to demonstrate how these parameters affect in propensity of SCC.

The following equation was determined empirically using Smith and Lazzara's experiments and makes necessary the proximate analysis:

$$
\operatorname{CSHT}_{V O L}=117\left(1-e^{-2.6 x}\right)
$$


Where $\mathrm{CSHT}_{\text {vol }}$ is the critical self-heating temperature in ${ }^{\circ} \mathrm{C}, \mathrm{x}$ is the moist fuel ratio and is calculated by:

$$
x=\frac{\left(\frac{\% \text { fixed carbon }}{\% \text { volatile matter }}\right)}{\% \text { moisture }}
$$

Table $6 \mathrm{CSHT}_{\text {vol }}$ index

\begin{tabular}{|c|l|}
\hline Temperature Range $\left({ }^{\circ} \mathbf{C}\right)$ & Propensity to SCC \\
\hline $\mathrm{CSHT}_{\text {vol }}<70$ & High Propensity \\
\hline $70<\mathrm{CSHT}_{\text {vol }}<100$ & Moderate Propensity \\
\hline $\mathrm{CSHT}_{\mathrm{vol}}>100$ & Low Propensity \\
\hline
\end{tabular}

This table shows that it is desirable to mine coals with $\mathrm{CSHT}_{\text {vol }}>100$ because it represents higher safety to the miners.

The U.S Geological Survey has the proximate analysis of 6679 different coal samples and used the value of $\mathrm{CSHT}_{\text {vol }}$ to classify their propensity to the spontaneous combustion based on the table above. Figure 22 shows the distribution of rank and propensity of SCC in United States.

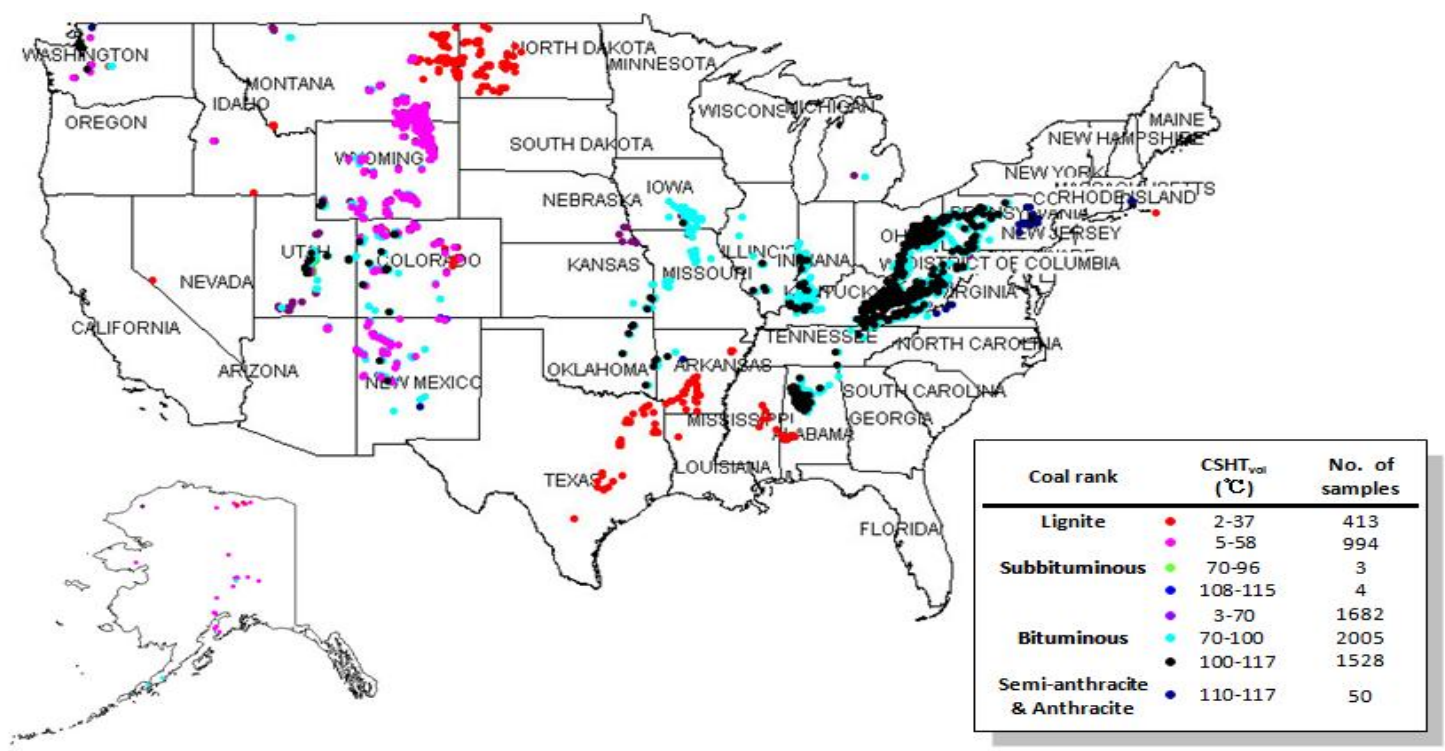

Figure 22- $\mathrm{CSHT}_{\text {vol }}$ distributed around USA 


\subsubsection{Quality Parameters Using TGA}

\subsubsection{Samples}

The samples used in the determination of the coal parameters were the same as the ones used in the previous experiments. Coal type C, D, Dm and E from Cerrejón Mine, Colombia.

The parameters used to characterize the Brazilian coal about its propensity to spontaneous combustion will be used in this chapter. The proximate analysis was done in Brazil.

\subsubsection{Equipment}

It was used in the determination of coal parameters; carbon content, ash, moisture and volatile matter the same equipments used in the determination of the activation energy of the coal: TA Q50, a computer with the software TA Universal Analysis installed.

\subsubsection{Experimental Procedures}

The coal sample used is ground to less than 50 mesh or lower than 297 $\mu \mathrm{m}$. Approximately $40 \mathrm{mg}$ is placed in the platinum pan and loaded into the furnace of the TA Q50.

The sample is heated to $110^{\circ} \mathrm{C}$ at a constant rate of $+85^{\circ} \mathrm{C} / \mathrm{min}$ with a constant nitrogen gas supply of $60 \mathrm{ml} / \mathrm{min}$. Then the sample is kept in isothermal condition for 3 minutes. The weight loss during this process this process is the amount of moisture in the coal. The sample continues to be heated to $900^{\circ} \mathrm{C}$ at the rate of $80^{\circ} \mathrm{C}$ for $7 \mathrm{~min}$ in a pure nitrogen environment. 
Then the temperature is maintained at $900^{\circ} \mathrm{C}$ for $7 \mathrm{~min}$. The weight loss during this process is the amount of volatile matter in the coal.

After this 7 minutes of isothermal condition, with the temperature still maintained at $900^{\circ} \mathrm{C}$, the gas supply is switched to pure oxygen at a flow rate of $60 \mathrm{ml} / \mathrm{min}$. The process will continue for 5 minutes and no weight loss will be observed. The residual weight at the end of the test is the ash content of the coal.

The figures below shows the measurement of the proximate analysis of the $C, D, D m$ and $E$ types of coal while the table 7 gives the values of the parameters of all coal samples.

\subsubsection{Results}

The proximate analysis using TGA method resulted for Cer-C coal composed by $3.95 \%$ moisture, $35.71 \%$ volatile matter, $45.82 \%$ carbon content and $14.52 \%$ ash.

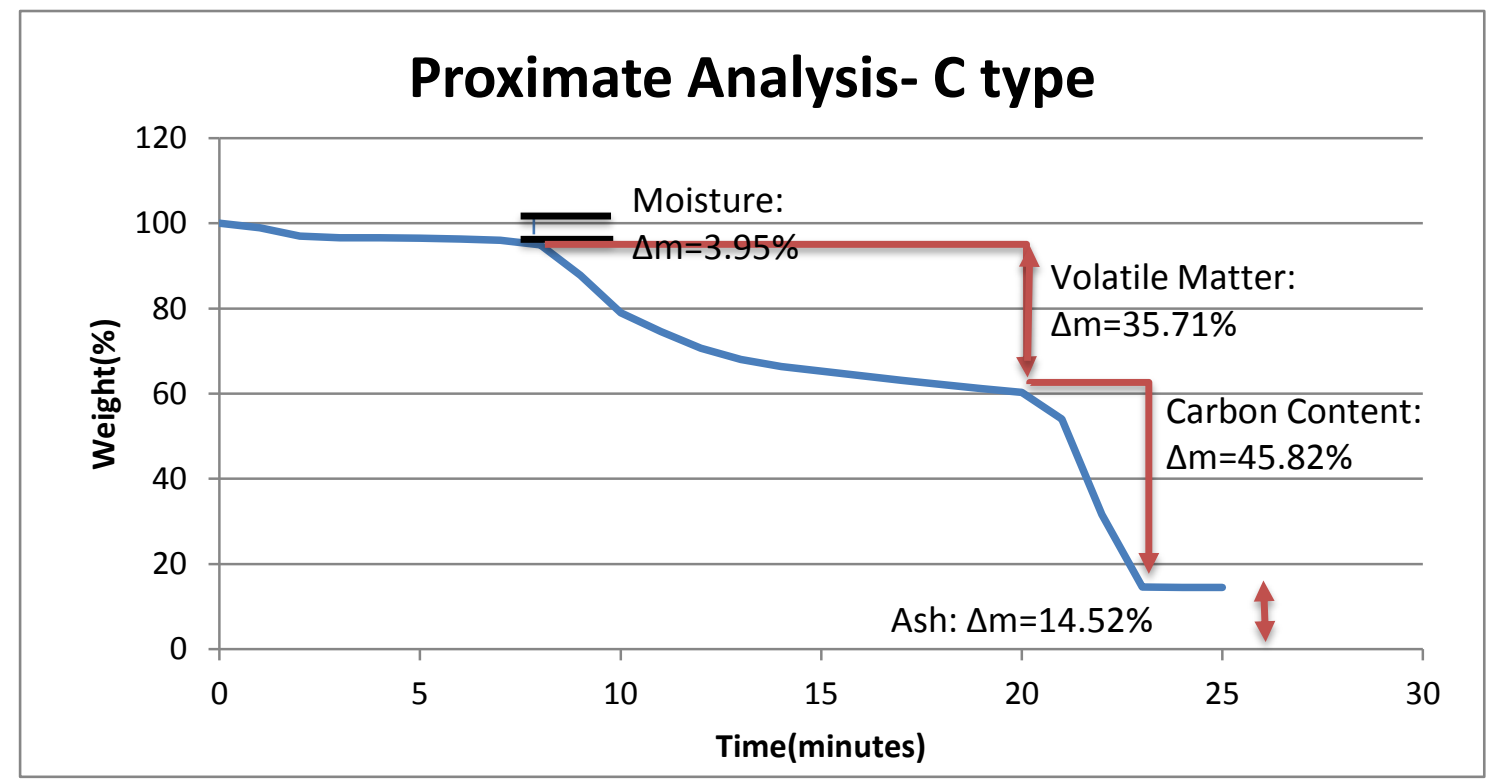

Figure 23- Proximate analisys of Cer-C coal 
The Cer-D coal is composed by $2.43 \%$ moisture, $31.12 \%$ volatile matter, 47.59\% carbon content and $18.86 \%$ ash.

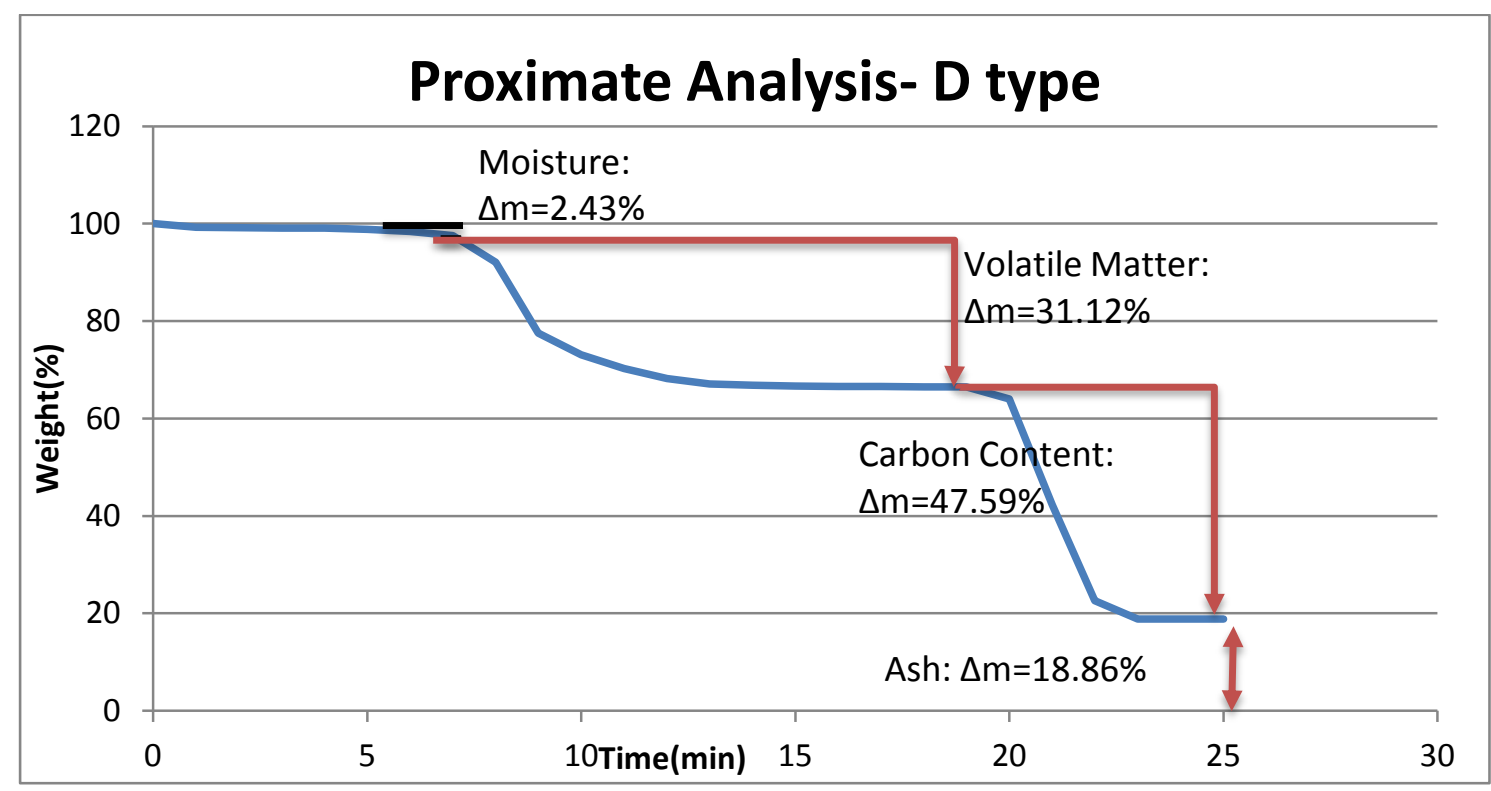

Figure 24- Proximate analisys of Cer-D coal

The coal Cer-Dm is composed by $4.58 \%$ moisture, $29.10 \%$ volatile matter, $43.30 \%$ carbon content and $23.02 \%$ ash. 


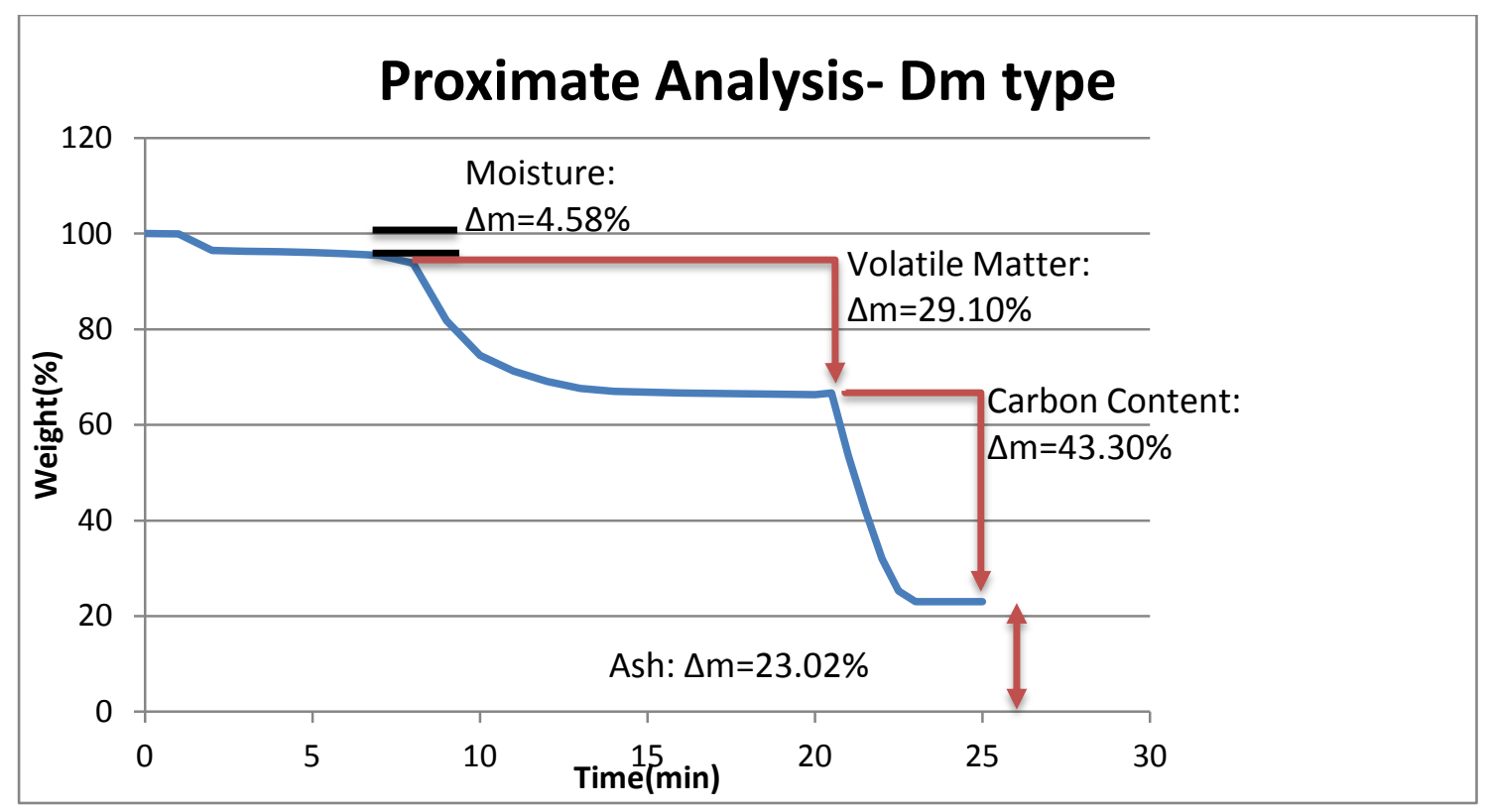

Figure 25- Proximate analisys of Cer-Dm coal

The Cer-E coal is composed by $0.46 \%$ moisture, 30.89 volatile matter, $45.00 \%$ carbon content and $23.65 \%$ ash.

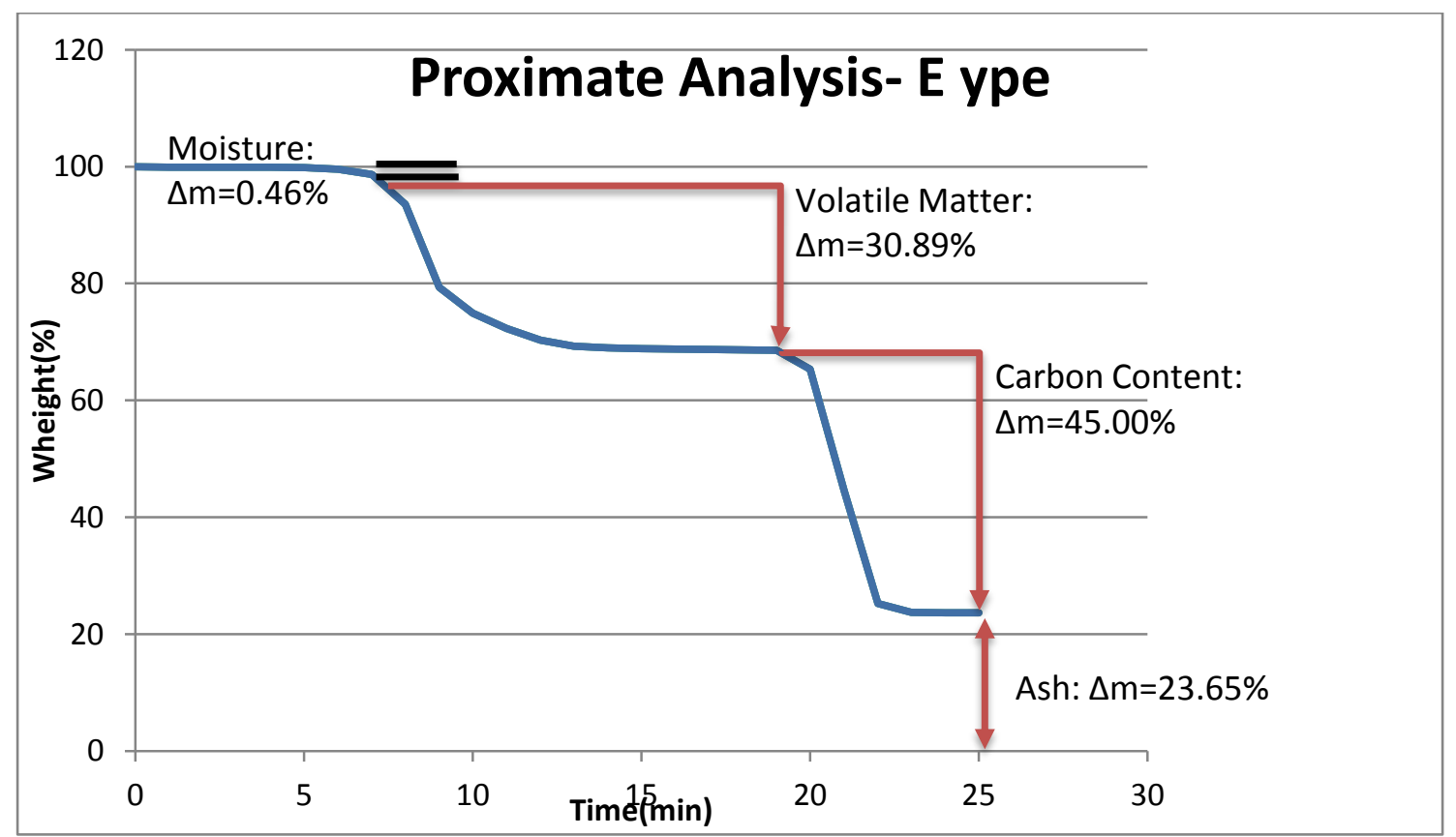

Figure 26- Proximate analisys of Cer-E coal 
Table 6 shows the values of $\mathrm{CSHT}_{\text {vol }}$ calculated using the proximate analysis of the Cerrejon coal samples and the proximate analysis done by CRM.

It is possible to see that the coals Cer-C and Cer-Dm have the higher potential to SCC because they have a lower value of CSHT while Cer-D and Cer-E have lower propensity to SCC. Finally, the proximate analysis from Brazilian coal demonstrated a high propensity to spontaneous combustion using the $\mathrm{CSHT}_{\text {vol }}$ equation as reference. However the USBM method overstates the moisture effects on the SCC potential. This method was improved and the value of the improved CSHT will be demonstrated later.

Table 7 CSHT Determination

\begin{tabular}{|c|c|c|c|c|c|c|}
\hline \multirow[b]{2}{*}{ Sample } & \multicolumn{4}{|c|}{ TGA (Wt \%) } & \multirow[b]{2}{*}{$\begin{array}{l}\text { Sulphur } \\
\text { Content }\end{array}$} & \multirow[b]{2}{*}{ USBM CSTH } \\
\hline & $\begin{array}{l}\text { Moisture } \\
\text { Content }\end{array}$ & $\begin{array}{l}\text { Volatile } \\
\text { Matter }\end{array}$ & Fixed Carbon & Ash Content & & \\
\hline Cer-E & 0.46 & 30.89 & 45 & 23.65 & 1.1 & 116.97 \\
\hline Cer-D & 2.43 & 31.12 & 47.59 & 18.86 & 1.07 & 94.22 \\
\hline Cer-C & 3.95 & 35.71 & 45.82 & 14.52 & 1.16 & 66.72 \\
\hline Cer-Dm & 4.58 & 29.1 & 43.3 & 23.02 & 1.03 & 66.73 \\
\hline CRM & 12.5 & 22.4 & 27.2 & 52.6 & 1.2 & 26.11 \\
\hline
\end{tabular}

From the calculation of the $\mathrm{CSHT}_{\text {vol, }}$, two Cer-E has low potential to spontaneous combustion,Cer-D has medium and Cer-C, Cer-Dm and CRM have high potential. 


\subsubsection{Quantification of Coal Rank}

\subsubsection{Coal Rank}

It is well known that the coal rank is an important factor to determine the SCC propensity; low ranked coal has high potential to spontaneous combustion while high ranked coal has low potential to spontaneous combustion.

The quantitative determination of coal rank was proposed by Suggate Suggate, 2000). His idea consists in creating a coal band that defines itself both in carbon-hydrogen and calorific value- volatile matter plots and then the coal band is scaled from $0-25$ according to the burial depth of different ranks of coal.

To determine the coal rank using the US coal band the following parameters $\mathrm{CV}_{\mathrm{dmmsf}}$ (calorific value on dry, mineral matter and sulfur-free basis in $B t u / l b$ ) and $V M_{d m m s f}$ (volatile matter on dry, mineral matter and sulfur-free basis in Btu/lb) must be determined and plotted in the figure 27 . The value of $\mathrm{FC}_{\mathrm{dmmsf}}$ must be determined in order to calculate $\mathrm{VM}_{\mathrm{dmmsf}}$. See the equations below.

$$
\begin{aligned}
\mathrm{FC}_{\mathrm{dmmsf}} & =\frac{100(F C-0.15 S)}{100-(\mathrm{M}+0.0108 \mathrm{~A}+0.0055 \mathrm{~S})} \\
\mathrm{CV}_{\mathrm{dmmsf}} & =\frac{100(F C-0.15 S)}{100-(0.0108 \mathrm{~A}+0.0055 \mathrm{~S})} \\
\mathrm{VM}_{\mathrm{dmmsf}} & =100-\left(\mathrm{FC}_{\mathrm{dmmsf}}\right)
\end{aligned}
$$

Where $\mathrm{CV}$ is the calorific value, $\mathrm{M}$ is the moisture content in $\%, \mathrm{~S}$ is the sulfur in \%, A is the ash in \%, FC is the fixed carbon in \%. 
Table 8 shows the parameters calculated of $\mathrm{CV}_{\mathrm{dmmsf}}, \mathrm{VM}_{\mathrm{dmmsf}}$ and quantified rank.

Table 8 Calculation of numerical coal rank

\begin{tabular}{|c|c|c|c|c|c|}
\hline Sample & CV (Btu/lb) & VMdmmsf & FCdmmsf & Btudmmsf & $\begin{array}{l}\text { Numerical Coal } \\
\text { Rank }\end{array}$ \\
\hline Cer-E & 10695,75 & 41,32 & 61,09 & 14408,01 & 12,9 \\
\hline Cer-D & 11417,7 & 39,71 & 61,91 & 14377,29 & 13,3 \\
\hline Cer-C & 11685,97 & 43,78 & 57,25 & 13895,69 & 12,2 \\
\hline Cer-Dm & 10273,21 & 40,24 & 61,64 & 13707,19 & 12,6 \\
\hline CRM & 5803,95 & 50,22 & 89,97 & 13505,01 & 9,2 \\
\hline
\end{tabular}

The position where the coal will occupy in the graph will determine the coal rank as follows (also based in US coal band):

It is possible to see that Brazilian and Colombian coal can be classified as bituminous because they are in the range 8-16 of the quantified coal rank.

Table 9 Quantified Coal Rank Range

\begin{tabular}{|l|l|}
\hline Lignite & $0-3$ \\
\hline Sub-bituminous & $3-8$ \\
\hline Bituminous & $8-16$ \\
\hline Semi-anthracite & $16-20$ \\
\hline Anthracite & $20-25$ \\
\hline
\end{tabular}




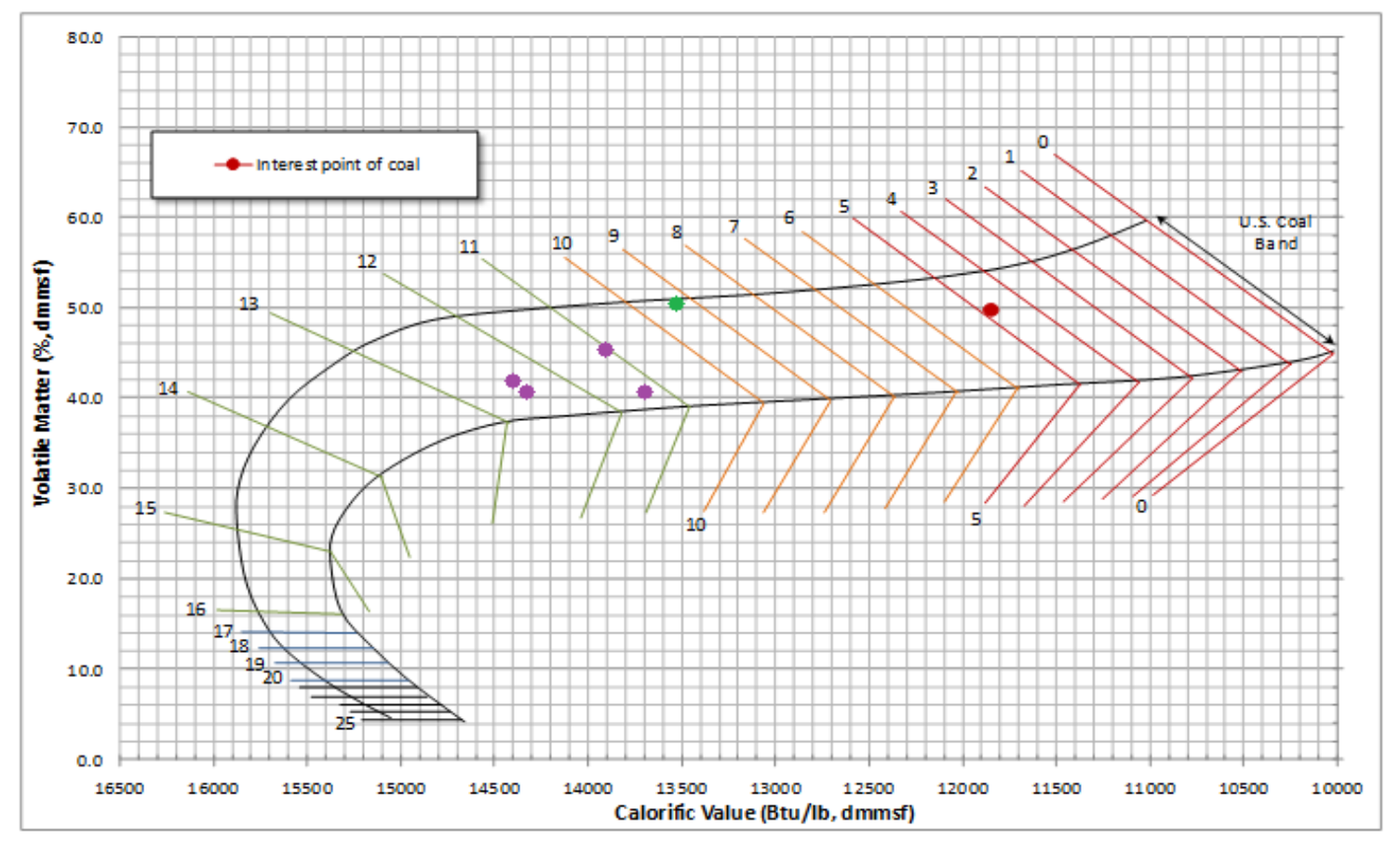

Figure 27 Quantified coal rank where green dot represents CRM coal and purple dots represents Cerrejon coal

\subsubsection{Improved CSHT Method}

The method of determining the critical self-heating temperature is a laboratory determined quantity that cannot be used to directly predict spontaneous ignition under specific real conditions. For this method is important having the proximate analysis and it is also important that the factors volatile matter, moisture, ash content and carbon content effects the propensity to spontaneous combustion. This method also provides risk index for rating and the most likely causes of this phenomenon.

This method used to determine the SHT (self-heating temperature) is based in a linear regression where the variables are the moisture $(M)$, carbon content (C) and volatile matter (V) and the result is SHT (Smith et Lazzara, 1987). See the correlations obtained: 


$$
S H T=\left\{\begin{array}{cc}
0.22 M-6.31 \frac{C}{V}+29.0 & 25<M \leq 35 \\
0.13 M+2.36 \frac{C}{V}+25.5 & 10<M \leq 25 \\
-4.95 M+2.66 \frac{C}{V}+88.3 & 1<M \leq 10 \\
36.1 M-5.29 \frac{C}{V}+108.3 & 0<M \leq 1
\end{array}\right.
$$

Table 10 Calculation of SHT of South American coal

\begin{tabular}{|c|c|c|c|c|c|c|c|}
\hline \multirow[b]{2}{*}{ Sample } & \multicolumn{4}{|c|}{ TGA (Wt \%) } & \multirow[b]{2}{*}{$\begin{array}{l}\text { Sulphur } \\
\text { Content }\end{array}$} & \multirow[b]{2}{*}{ USBM CSTH } & \multirow[b]{2}{*}{ SHT $\left({ }^{\circ} \mathrm{C}\right)$} \\
\hline & $\begin{array}{l}\text { Moisture } \\
\text { Content }\end{array}$ & Volatile Matter & $\begin{array}{l}\text { Fixed } \\
\text { Carbon }\end{array}$ & $\begin{array}{c}\text { Ash } \\
\text { Content }\end{array}$ & & & \\
\hline Cer-E & 0.46 & 30.89 & 45 & 23.65 & 1.10 & 116.97 & 117.2 \\
\hline Cer-D & 2.43 & 31.12 & 47.59 & 18.86 & 1.07 & 94.22 & 80.34 \\
\hline Cer-C & 3.95 & 35.71 & 45.82 & 14.52 & 1.16 & 66.72 & 72.16 \\
\hline Cer-Dm & 4.58 & 29.1 & 43.3 & 23.02 & 1.03 & 66.73 & 69.59 \\
\hline CRM & 12.5 & 22.4 & 27.2 & 52.6 & 1.2 & 26.11 & 29.99 \\
\hline
\end{tabular}

The improved SHT method demonstrates a similar result comparing with the USBM evaluation. From them one of the coal Cer-E has low, Cer-D and Cer-C have moderate and Cer-Dm and CRM have high propensity to spontaneous combustion.

\subsubsection{Correlation between Quantified Coal Rank (QCR) and SHT}

It was demonstrated before how to evaluate the coal rank in a quantified manner using the values of $\mathrm{CV}_{\mathrm{dmmsf}}$ and $\mathrm{VM}_{\mathrm{dmmsf}}$ and plotting in the chart of Figure 28.

A plot of the SHT against their respective QCR results in a nonlinear relationship. Sub-bituminous has the lowest SHT. Although lignite has the lowest rank, its SHT is higher than that of sub-bituminous. High volatile bituminous $C, B, A$ and medium to low volatile bituminous coal have higher coal rank and SHT, which means lower propensity to spontaneous combustion. 
The SHT of those samples were determined using the improved method and plotted in the chart. See that the samples from Colombia and Brazil fits well in Figure 29.

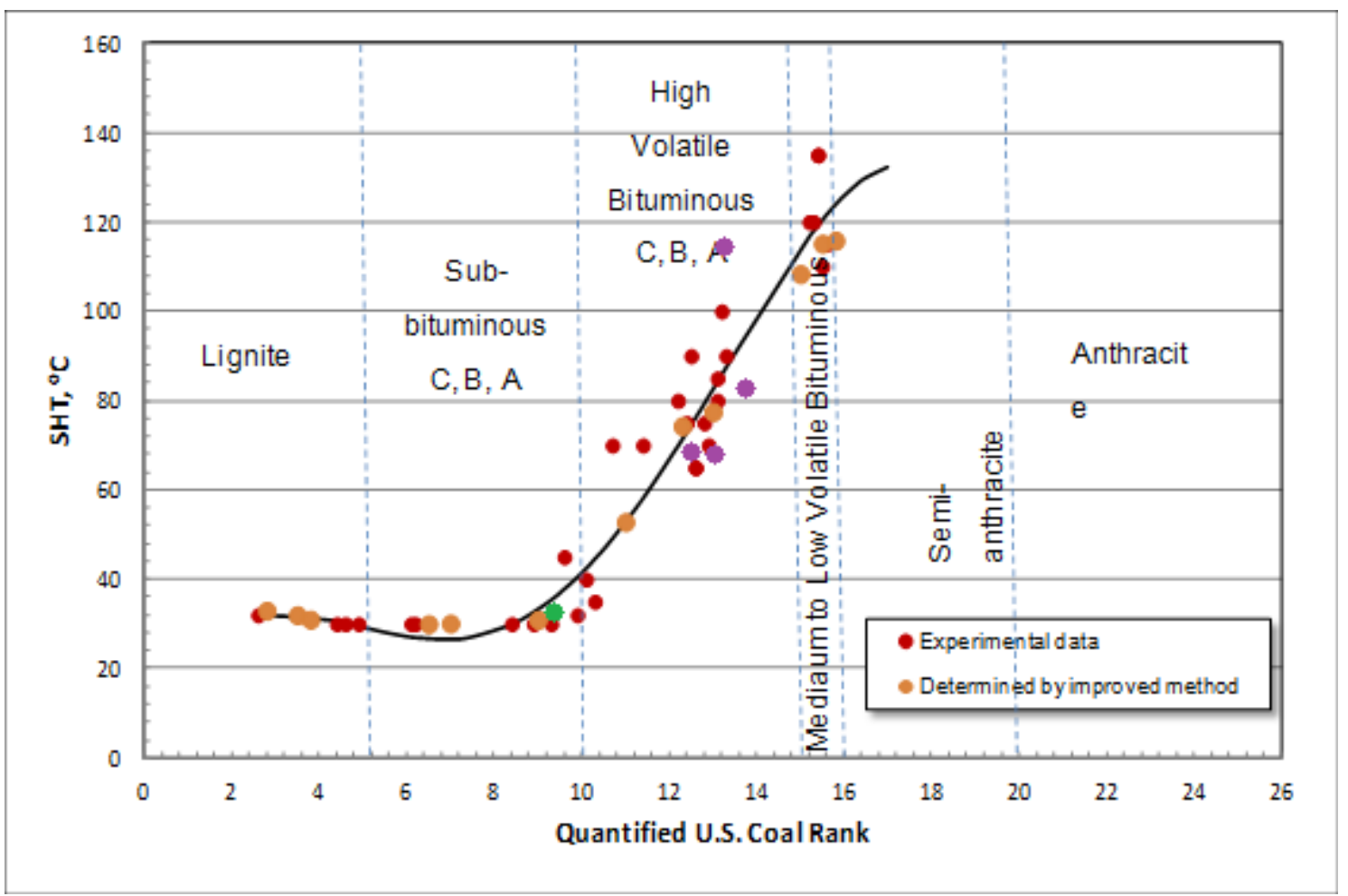

Figure 28 SHT versus QCR (Wang, 2014)

\subsubsection{Summary}

There are many methods to determine the propensity of spontaneous combustion of coal using the proximate analysis and USBM methods. The TGA Q50 was important to determine values like activation energy and proximate analysis is a short period of time.

Thousands of coal samples were used to determine the coal rank quantitatively, in a scale from 0 to 25 , by calculating the data adjusting the dry, mineral matter and sulfur-free basis (dmmsf) basis for calorific value and volatile matter and plotted into a diagram. 
The values of SHT were calculated using a previous and an improved method. The improved method showed itself more accurate in relation to the experimental values of $\mathrm{SHT}\left({ }^{\circ} \mathrm{C}\right)$ than the first proposed method to calculate SHT.

The relationship between the improved $\mathrm{SHT}$ and QCR is a nonlinear curve. This curve can give a quick estimate of the self-heating temperature of US coal and will be used as a reference to the coal samples of this work.

The proximate analysis, activation energy, SHT results from the three methods and quantified coal rank for all the samples will be listed in the table 9.

Table 14 Summary of the parameters calculated to charachterize propensity to spontaneous combustion of Colombian and Brazilian coal.

\begin{tabular}{|c|c|c|c|c|c|c|}
\hline Sample & SHT & $\begin{array}{l}\text { USBM } \\
\text { CSTH }\end{array}$ & $\begin{array}{l}\text { Numerical } \\
\text { Coal } \\
\text { Rank }\end{array}$ & ASTM Rank & $\begin{array}{l}\text { Activation } \\
\text { Energy } \\
(\mathrm{kJ} / \mathrm{mol})\end{array}$ & $\begin{array}{l}\text { R70 Dry/Moist } \\
\text { Oxygen }\end{array}$ \\
\hline Cer-E & 117.2 & 116.97 & 12.9 & $\mathrm{HvAb}$ & 14.04 & low/1.03 \\
\hline Cer-D & 80.34 & 94.22 & 13.3 & $\mathrm{HvAb}$ & 17.72 & low/0.38 \\
\hline Cer-C & 72.16 & 66.72 & 12.2 & $\mathrm{HvAb}$ & 15.54 & low/1.94 \\
\hline Cer-Dm & 69.59 & 66.73 & 12.6 & $\mathrm{HvBb}$ & 13.5 & low/2.26 \\
\hline CRM & 29.99 & 26.11 & 9.2 & $* *$ & $* *$ & $* *$ \\
\hline
\end{tabular}




\section{Conclusions and Prospects for Future Research}

\subsection{General Conclusion}

Spontaneous combustion of coal has been the cause of environmental, economic and safety problems around the world. Many factors, such as moisture, volatile matter, pyrite, fixed carbon, coal rank, can affect the spontaneous combustion. Scientists have developed several methods for determining the potential to self-ignition of coal. These methods have been used to analyze coals from many countries in order for better understanding and reliable prediction of spontaneous combustion for further safety and health improvement. But they have not been used to classify the spontaneous combustion propensity of South American coals. The objective of this research was to understand the potential of self-ignition of South American coal using the existing methods. The conclusions of this reserch are:

- From the $\mathrm{R}_{70}$ method, the coal from Colombia (biggest coal reserve in Latin America) demonstrated low propensity to spontaneous combustion $\left(R_{70}<1.0^{\circ} \mathrm{C} / \mathrm{h}\right)$ in a dry oxygen inflow environment. The same samples were used to determine $R_{70}$ in moist oxygen environment and it was observed a considerable higher self-heating rate. The Cer-Dm coal is most reactive and the Cer-D coal is less reactive.

- The TGA experimental method has been used to determine the spontaneous combustion propensity of the Colombian coal samples. It shows that the reactivity of the coal samples in the following order from the least to the most reactive: Cer-D, Cer-C, Cer-E and Cer-Dm. The 
extremes values of this order are the same as the ones obtained from $\mathrm{R}_{70}$ experiments. However, by comparing the South American coals with coals from other places, like China and US, the derived activation energies does not seem to be a good parameter to compare coal from very distinct places.

- The obtained parameters SHT's show that the coal Cer-E has low propensity to spontaneous combustion, Cer-C and Cer-D have medium and Cer-Dm and CRM have high propensity.

- The obtained parameters CSHT vol's show that coal Cer-E has low propensity to spontaneous combustion, Cer-D medium and Cer-C, CerDm and CRM have high propensity to spontaneous combustion.

- The quantified coal ranks show that the ranks of the Brazilian coals are lower than those of Colombian coals. It means that the Brazilian coals have higher propensity to spontaneous combustion than the Colombian coals.

- Based on the relationship between the self-heating temperature and the quantified coal rank, the Brazilian coals appear to be in the subbituminous region with higher propensity to spontaneous combustion while the Colombian coals are in the high volatile bituminous region with medium to low propensity to spontaneous combustion. 


\subsection{Recommendations for Future Research}

It should be noted that most of the regressions used to calculate the parameters such as $\mathrm{SHT}, \mathrm{CSHT}_{\mathrm{vol}}, \mathrm{CV}_{\mathrm{dmmsf}}, \mathrm{VM}_{\mathrm{dmmsf}}, \mathrm{FC}_{\mathrm{dmmsf}}$, were derived from the testing data from the US coal samples. These regressions were used in this research due to the lack of studies about spontaneous combustion of the South American coals. Therefore, more testing should be performed on the South American coals for generating more accurate empirical relationships for similar studies about South American coals.

The number of samples used in this research was small. The number of experiments using similar coals and coals from other deposits should be done to have more accurate and complete classification of South American coals. 


\section{References}

ASTM, 1988, Compositional Analysis by Thermogravimetry.

Beamish, B.B., 2005, "Comparison of the R70 self-heating rate of New Zealand and Australian coals to Suggate rank parameter" International Journal of Coal Geology, Vol. 64, pp. 139-144

BPstats, June 2015, "BP Statistical Review of World Energy-Coal”.www.bp.com

Cray, D., 2010 “Deep Underground, Miles of Hidden Wildfires Rage," Time Magazine.content.time.com/time/health/article/0,8599,2006195,00.html

Davis, Joseph and Reynolds, 1928,Spontaneous Heating of Coal. U.S. Dept. of Commerce, Bureau of Mines

Kaymakci, E., Didari, V., 2000, "Relations between Coal Properties and Spontaneous Combustion Parameters". Turkish J. Eng. Env. Sci.

Hartman, H.L., L.H., Mutmansky, J.M. Ramani, R.V. and Wang, Y.J., 1998, "Mine Ventilation and Air Conditioning" 3rd Ed., New York: John Wiley \& Sons.

O'Keefe,J., Bechtel,A., Christanis K., Dai,S., DiMichele, W. ,Eble, C., Esterle,J., Mastalerz, M., Raymond, A., Valentim, B. , Wagner, N., Ward, C., Hower, J., 2013, "On the fundamental difference between coal rank and coal type". International Journal of Coal Geology.

Yu, J., Jiang, Y., Tahmasebi, A., Han, Y., Li, X., Lucas, J., Wall, T., 2013, "Coal oxidation under mild conditions: current status and applications". Chemical Engineering \& Technology.

Singh, Ran, 2013, "Spontaneous Heating and Fire in Coal Mines”. 
Mazumdar, B.K., 1996, "On the correlation of moist fuel ratio of coal with its spontaneous combustion temperature," Fuel, Vol. 75, pp. 646-648.

Rennie, David, 2002, "How China's scramble for 'black gold' is causing a green disaster," The Daily Telegraph (London). Retrieved 30 April 2010.

Stephan, C.R., 1990, Coal Dust Explosion Hazards, MSHA Report, No. 01-06690.

Suggate, R.P., 2000, "The rank (Sr) scale: its basis and its applicability as a maturity index for all coals," New Zealand Journal of Geology \& Geophysics, Vol. 43, pp. 521-553.

Tao Xu, De-Ming Wang, Qi-lin He, 2013, "The study of the critical moisture content at which coal has the most high tendency to spontaneous combustion".

Thomas, Larry, 1992, Handbook of Practical Coal Geology.

Wang, Xinyang, 2014, Experimental and Theoretical Studies of Kinetics and Quality Parameters to Determine Spontaneous Combustion Propensity of U.S. Coals.

Wantaek Jo, Hokyung Choi, Sangdo Kim, Jiho Yoo, Donghyuk Chun, Youngjoon Rhim, Jeonghwan Lim, Sihyun Lee, 2013, "A comparison of spontaneous combustion susceptibility of coal according to its rank".

Wiwik Sujanti, Dong-ke Zhang, 1998, "A laboratory study of spontaneous combustion of coal: the influence of inorganic matter and reactor size". 